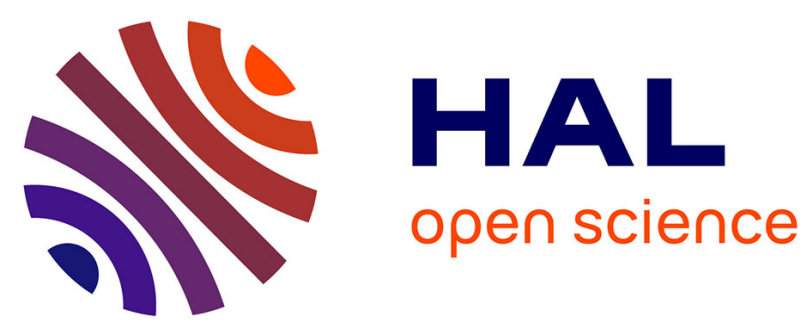

\title{
Effect of phosphorous-modified silica on the flame retardancy of polypropylene based nanocomposites
}

Julie Courtat, Flavien Mélis, Jean-Marie Taulemesse, Véronique

Bounor-Legaré, Rodolphe Sonnier, Laurent Ferry, Philippe Cassagnau

\section{To cite this version:}

Julie Courtat, Flavien Mélis, Jean-Marie Taulemesse, Véronique Bounor-Legaré, Rodolphe Sonnier, et al.. Effect of phosphorous-modified silica on the flame retardancy of polypropylene based nanocomposites. Polymer Degradation and Stability, 2015, 119, pp.260-274. 10.1016/j.polymdegradstab.2015.05.022 . hal-01221767

\section{HAL Id: hal-01221767 https://hal.science/hal-01221767}

Submitted on 4 Jun 2021

HAL is a multi-disciplinary open access archive for the deposit and dissemination of scientific research documents, whether they are published or not. The documents may come from teaching and research institutions in France or abroad, or from public or private research centers.
L'archive ouverte pluridisciplinaire $\mathbf{H A L}$, est destinée au dépôt et à la diffusion de documents scientifiques de niveau recherche, publiés ou non, émanant des établissements d'enseignement et de recherche français ou étrangers, des laboratoires publics ou privés. 


\title{
Effect of phosphorous-modified silica on the flame retardancy of polypropylene based nanocomposites
}

\author{
Julie Courtat ${ }^{\mathrm{a}}$, Flavien Melis ${ }^{\mathrm{a}}$, Jean-Marie Taulemesse ${ }^{\mathrm{b}}$, Véronique Bounor-Legare ${ }^{\mathrm{a}}$, \\ Rodolphe Sonnier $^{\mathrm{b},{ }^{*}}$, Laurent Ferry ${ }^{\mathrm{b}}$, Philippe Cassagnau ${ }^{\mathrm{a}}$ \\ a Université Claude Bernard Lyon 1, Ingénierie des Matériaux Polymères, IMP@Lyon1, UMR CNRS 5223, Bât. Polytech, 15 Bd. A. Latarjet, 69622 Villeurbanne \\ Cedex, France \\ ${ }^{\mathrm{b}}$ Centre des Matériaux de l'Ecole des Mines d'Alès, 6 avenue de Clavières, 30319 Alès Cedex, France
}

\begin{abstract}
A B S T R A C T
Surface modification of various silicas by phosphorous agents was carried out with the aim to use these particles as flame retardant additive in a polypropylene matrice (PP) at low content (10 wt\%). Thermal and flammability properties of PP/modified silica (PP-Tm-10\%, PP-Zm-10\%) were studied using TGA, PCFC and cone calorimeter and compared to those conferred by pure silica (PP-T-10\%, PP-Z-10\%). Quite surprisingly the untreated fillers induce the most significant reduction of peak of Heat Release Rate (50\% decrease) while the surface modification by phosphorous agents does not lead to the expected effect on the fire behavior of PP composite. This phenomenon was related to the morphology and rheological behavior of the various PP composites. Indeed, the higher the storage modulus at low frequencies is, the better the fire behavior is, because of the induced barrier effect. Moreover, the addition of non modified silicas leads to a decrease of $10 \mathrm{~s}$ of the TTI. This phenomenon was related to the formation of bubbles after the PP melting during cone calorimeter test.
\end{abstract}

Keywords:

Silica

Surface modification

PP

Dispersion

Rheology

Flame retardancy

Phosphorus

\section{Introduction}

Fire retardancy of polypropylene (PP) has been extensively addressed [1-11]. It is one of the most difficult polymers to be fireproofed due to its non-charring behavior and high heat release (around $40 \mathrm{~kJ} / \mathrm{g}$ [12]). Nowadays, phosphorus fire retardants (FR) are considered as the best alternative to toxic halogenated additives. Phosphorous FR can act in the condensed phase (by enabling the creation of crosslinked and charred structure, more particularly in polymers containing oxygen) or/and in the gas phase (by scavenging high energy radicals $\mathrm{H}^{\bullet}$ and $\mathrm{OH} \cdot$ thanks to the formation of active radicals as $\mathrm{PO} \cdot \mathrm{PO}_{2}$ and $\mathrm{HPO} \cdot$ ) [13]. Especially, APP has been used in combination with charring agents and other synergists to form efficient intumescent flame retardant systems $[2,3,8,9]$. These systems act by promoting an insulating expanded char layer at the surface of the sample during combustion. However concentration

\footnotetext{
* Corresponding author.

E-mail address: rodolphe.sonnier@mines-ales.fr (R. Sonnier).
}

of additives is at least $20 \mathrm{wt} \%$ to obtain a reasonable improvement of the fire behavior, with a limiting oxygen index (LOI) of $30 \%$ and a $\mathrm{V}-0$ classification in the UL-94 test $[3,8,9]$. Many types of filler have also been used in order to improve the thermal and fire stability of PP, as carbon nanotubes, fullerene and silica [14-22].

It has been showed that the addition of only $10 \mathrm{wt} \%$ of silica leads to a decrease of at least $25 \%$ of the pHRR of PP in cone calorimeter tests, depending of the porosity of the silica [23,24]. Indeed, Gilman and Kashiwagi pointed out that a highly porous silica (as silica gel with a pore volume of $3 \mathrm{~cm}^{3} / \mathrm{g}$ ) retards mass transfer due to a restriction of mobility of the polymer chains or because the high pore volume silica gels can accommodate the PP macromolecules or its decomposition products. According to the type of silica, the viscosity of the $\mathrm{PP} /$ silica composite changes: high pore volume silica gel and hydrophilic fumed silica lead to higher viscosity than fused silica or hydrophobic fumed silica because of different interactions between fillers and the polymer matrix. Some studies have been already carried out to show the influence of the viscoelasticity of polymer on the fire behavior [24-31]. As said above, Kashiwagi et al. have already shown that the incorporation of $10 \%$ by weight of different 
silicas in PP can lead to different viscoelastic properties. The viscosity may have an influence both on the bubbling of the composite and the accumulation of the fillers on its surface during the combustion of the material. The formation of a protective layer of fillers can lead to the improvement of fire behavior by reducing heat and gas transfer between the flame and the condensed phase. Fina et al. have also shown that bubbles can modify the in-depth heat transfer by scattering the incoming radiation [32].

Usually, fillers are used in combination with flame retardant systems in order to have a synergist effect as a reinforcement of the char, and a promotion of the barrier effect thanks to the layer formed during pyrolysis [33]. Some studies have shown the interest of the surface modification of silica by DOPO (9,10-dihydro-9-oxa10-phosphaphenanthrene-10-oxide) compared with the simultaneous addition of silica and DOPO on thermal stability of PP [34]. Dong et al. pointed out the synergistic effect of $3.2 \mathrm{wt} \%$ of DOPO immobilized on silica nanoparticles ( $5 \mathrm{wt} \%$ in PP) with an enhancement of the thermal stability of $90^{\circ} \mathrm{C}$ under air. This result is higher than the one obtained when $5 \mathrm{wt} \%$ of silica + DOPO are introduced in $\mathrm{PP}$ (that shows an increase of $51^{\circ} \mathrm{C}$ ). The authors also added $1 \mathrm{wt} \%$ of the silica modified by DOPO in PP in association with $25 \mathrm{wt} \%$ of an intumescent system (APP/PER 2/1 w/w) [35]. Such a composite had better fire properties than PP containing only 25 wt\% of APP/PER, with a V-0 classification and a LOI of $32.1 \%$. The synergistic effect of DOPO immobilized on silica seems to lead to the formation of a more stable char residue, as well as an increase of the viscosity of the composite. However this study does not assess the influence of the modified silica alone on the fire behavior of PP, and no conclusion can be drawn on grafting ratio and the minimal filler rate to introduce in order to fireproof PP. Once again, the viscosity of materials seems to be an important parameter influencing fireproofing mechanism.

The aim of this study is to combine the effect of fillers and phosphorous flame retardants by grafting a phosphorous agent onto silica. Thermal and flammability properties of the PP/modified silica composites will be studied and compared to the systems with unmodified fillers. This work will also show how spherical fillers can influence the viscosity of PP in the molten state and influence the fire behavior of composite.

\section{Experimental}

\subsection{Materials and reagents}

Different types of silica were provided by Solvay. Table 1 shows the main characteristics of these fillers. These silicas consist of an agglomeration of primary spherical particles of about few nanometers in diameter. Diethylphosphatoethyltriethoxysilane (SiP, 92\%) was supplied by ABCR. PP (PPC 7760) was supplied by Total. According to the technical data sheet from Total, PPC 7760 is a heterophasic copolymer with a melt flow index of $15 \mathrm{~g} / 10 \mathrm{~min}$. Its melting point is $165{ }^{\circ} \mathrm{C}$. All these products were used as received without further purification.

$$
\begin{array}{ccc}
\text { Silica } & \mathrm{SiP} & \text { Grafted silica } \\
(1) \equiv \mathrm{SiOH}+\mathrm{HOSi} \equiv & \longrightarrow & \equiv \mathrm{SiOSi} \equiv+\mathrm{HOH} \\
(2) \equiv \mathrm{SiOH}+\mathrm{R}^{\prime} \mathrm{OSi} \equiv & \longrightarrow & \equiv \mathrm{SiOSi} \equiv+\mathrm{R}^{\prime} \mathrm{OH}
\end{array}
$$

Fig. 1. Scheme showing the condensation reactions between silica and SiP.

\subsection{Modification of silica}

Precipitated silica Tixosil T365 and Zeosil 1165 MP were modified with $\mathrm{SiP}$ and are respectively named $\mathrm{Tm}$ and $\mathrm{Zm}$. In both cases, $100 \mathrm{~g}$ of dried silica were dispersed in $1 \mathrm{~L}$ of toluene for $1 \mathrm{~h}$ with continuous stirring under argon: then $50 \mathrm{~g}$ of alkoxysilane were added [36]. After $48 \mathrm{~h}$ of reaction, solvent was removed by evaporation and the resulting solid was dried at $80{ }^{\circ} \mathrm{C}$ overnight in vacuum and washed with isopropyl alcohol thanks to a soxhlet extractor. Eventually, samples were dried once again at $80{ }^{\circ} \mathrm{C}$ overnight in vacuum.

The grafting process of SiP onto the silica is based on hydrolysis-condensation reactions between the hydroxyl groups at the silica surface and the alkoxysilane according to the reactional scheme presented in Fig. 1(1) and (2).

\subsection{Preparation of PP composites}

Various types of silica were incorporated into PP using a Leistritz LSM30-34 ( $\mathrm{D}=34 \mathrm{~mm}, \mathrm{~L} / \mathrm{D}=34)$ co-rotating twin-screw extruder at the temperature of $190{ }^{\circ} \mathrm{C}$. The rotation speed was kept to $150 \mathrm{rpm}$ and polymer flow rate was $3 \mathrm{~kg} / \mathrm{h}$. Then composites were granulated and injection molded at $190{ }^{\circ} \mathrm{C}$ using 50 Krauss-Maffei apparatus (Munich, Germany) to obtain samples with dimensions $100 \times 100 \times 4 \mathrm{~mm}^{3}$.

Composites were prepared using silicas presented in Table 1. $10 \mathrm{wt} \%, 15 \mathrm{wt} \%$ and $20 \mathrm{wt} \%$ (when it was experimentally possible) of each silica were introduced into PP in order to study the influence of the types of silica on the fire behavior. Moreover, PP composites containing $10 \mathrm{wt} \%$ of SiP modified T365 and Z1165MP (respectively $\mathrm{Tm}$ and $\mathrm{Zm}$ ) were prepared.

\subsection{Characterization}

\subsubsection{Elemental analysis}

Elemental analysis was conducted at the Institut des Sciences Analytiques (ISA, CNRS, Villeurbanne). Silicon and Phosphorus contents were determined by ICP-AES (inductively coupled plasmaatomic emission spectrometer) and carbon content by either catharometry or specific infrared detectors.

\subsubsection{Thermogravimetric analysis (TGA)}

Thermogravimetric analysis (TGA) of silicas and grafted silicas were performed using a TA SDT Q600 thermal analyzer with a scan rate of $10{ }^{\circ} \mathrm{C} / \mathrm{min}$ from room temperature to $800{ }^{\circ} \mathrm{C}$ under air. Thermal analyses of composites were carried out at $10^{\circ} \mathrm{C} / \mathrm{min}$ from

\begin{tabular}{|c|c|c|c|c|c|}
\hline & Commercial name & Particle size $(\mu \mathrm{m})$ & Humidity (\%wt) & BET surface area $\left(\mathrm{m}^{2} / \mathrm{g}\right)$ & Porosity $\left(\mathrm{cm}^{3} / \mathrm{g}\right)$ \\
\hline T365 & Tixosil T365 & $3.5-4$ & 5.3 & 168 & 7.91 \\
\hline Z1165MP & Zeosil 1165 MP & 250 & 6.7 & 173 & 3.13 \\
\hline T38X & Tixosil T38X & 200 & $\leq 8$ & $\approx 160$ & 2.1 \\
\hline Z $200 \mathrm{MP}$ & Zeosil premium $200 \mathrm{MP}$ & 200 & $5-8$ & 222 & 3.37 \\
\hline HRS $1200 \mathrm{MP}$ & Zeosil HRS $1200 \mathrm{MP}$ & 200 & $5-8$ & 182 & 3.88 \\
\hline HDK (Hydrophobic) & HDK H20 & NA & $<0.6$ & 170 & $\mathrm{NA}^{\mathrm{a}}$ \\
\hline Sidistar T120 & Sidistar T120 & 0.15 & NA & $15-30$ & $\approx 0$ \\
\hline
\end{tabular}

Table 1

Characteristics of silica.

\footnotetext{
${ }^{\mathrm{a}} \mathrm{NA}=$ Non Analyzed.
} 
room temperature to $600{ }^{\circ} \mathrm{C}$ under nitrogen or air flow using a TA Q500 TGA. The tests performed under air atmosphere enable to study the thermal oxidative degradation of PP that plays a major role in fire tests before flaming and thus may control the time to ignition. The tests performed under nitrogen atmosphere enable to study the anaerobic pyrolysis of materials which is the main degradation pathway after ignition. The second set of tests can be compared to PCFC analysis conditions.

\subsubsection{Solid ${ }^{29} \mathrm{Si}$ and ${ }^{31} \mathrm{P}$ HPDEC NMR}

${ }^{29} \mathrm{Si}$ and ${ }^{31} \mathrm{P}$ NMR analyses were performed using an Advance 300 Bruker spectrometer. HPDEC-MAS NMR spectra were recorded at room temperature by using a $4 \mathrm{~mm}$ MAS probe. The ${ }^{29} \mathrm{Si}$ and ${ }^{31} \mathrm{P}$ spectra were recorded at $59.63 \mathrm{MHz}$ and $121.51 \mathrm{MHz}$ respectively.

Analyses were conducted at ICL C2P2 (UMR 5265 CNRS - CPE Université Lyon 1).

\subsubsection{Scanning Electron Microscopy (SEM)}

A Scanning Electron Microscope (FEI Quanta 200 SEM) was used to study the morphology of the samples. The composites were cryofractured using liquid nitrogen and then sputter coated with carbon. The specimens were placed under high vacuum before being analyzed at an accelerating voltage of $10 \mathrm{kV}$ for the different silicas and $15 \mathrm{kV}$ for composites.

\subsubsection{Rheology}

The rheological behavior of composites was analyzed with a Rheometrics AR2000 mechanical spectrometer equipped with a $25 \mathrm{~mm}$ parallel plate geometry. Complex viscosity measurements were carried out with an oscillation test at $200{ }^{\circ} \mathrm{C}$ using $0.5 \%$ strain and an angular frequency ranging from $10^{-1} \mathrm{rad} / \mathrm{s}$ to $10^{2} \mathrm{rad} / \mathrm{s}$.

Samples were prepared by compression molding at $190^{\circ} \mathrm{C}$ in the form of $25 \mathrm{~mm}$ in diameter and $1 \mathrm{~mm}$ thick discs.

\subsubsection{Fire behavior}

The flammability properties of the composites were estimated using a Pyrolysis Combustion Flow Calorimeter (PCFC) analysis. Tests were carried out in duplicate according to the anaerobic pyrolysis method of the ASTM D7309 (method A) using a FTT apparatus. $2-4 \mathrm{mg}$ of sample was pyrolyzed under nitrogen flow up to $750{ }^{\circ} \mathrm{C}$ at a heating rate of $1^{\circ} \mathrm{C} / \mathrm{s}$. Gases are extracted and sent to a combustion chamber in presence of $\mathrm{O}_{2} / \mathrm{N}_{2}(20 / 80)$ with a controlled constant flow of $100 \mathrm{~cm}^{3} / \mathrm{min}$. The combustion temperature was fixed at $900{ }^{\circ} \mathrm{C}$ in order to reach a complete combustion. The oxygen depletion during the test allows calculating the Heat Release Rate (HRR) according to the Huggett's relation [37] (1 kg of consumed oxygen corresponds to $13.1 \mathrm{MJ}$ of released energy).

The flammability of the samples was also determined by a Fire Testing Technology FTT Cone Calorimeter. Tests were performed in accordance with the International Standard ISO 5660-1, using aluminum foil in order to prevent dripping of molten material. The specimens $\left(100 \times 100 \mathrm{~mm}^{2}\right.$ section, $4 \mathrm{~mm}$ thickness $)$ were horizontally exposed to an irradiance of $50 \mathrm{~kW} / \mathrm{m}^{2}$. Each formulation was tested in duplicate. Peak of heat release rate (pHRR), Total Heat Release (THR), Time To Ignition (TTI), Residual mass and Effective Heat of Combustion (EHC) are reported.

The uncertainties in measurements for both apparatus are about $5 \%$ and $15 \%$ respectively.

To get an insight on ignition, the upper surface temperature of composites was also measured by an infrared (IR) camera (Optristemperature range $125-900^{\circ} \mathrm{C}$ ) during a cone calorimeter test. The specimens were exposed to an irradiance of $15 \mathrm{~kW} / \mathrm{m}^{2}$ in order to highlight phenomena that could take place at $50 \mathrm{~kW} / \mathrm{m}^{2}$ before ignition. Specimens were places $60 \mathrm{~mm}$ under the conic heater. The IR camera was placed in an inclined position above the specimen.

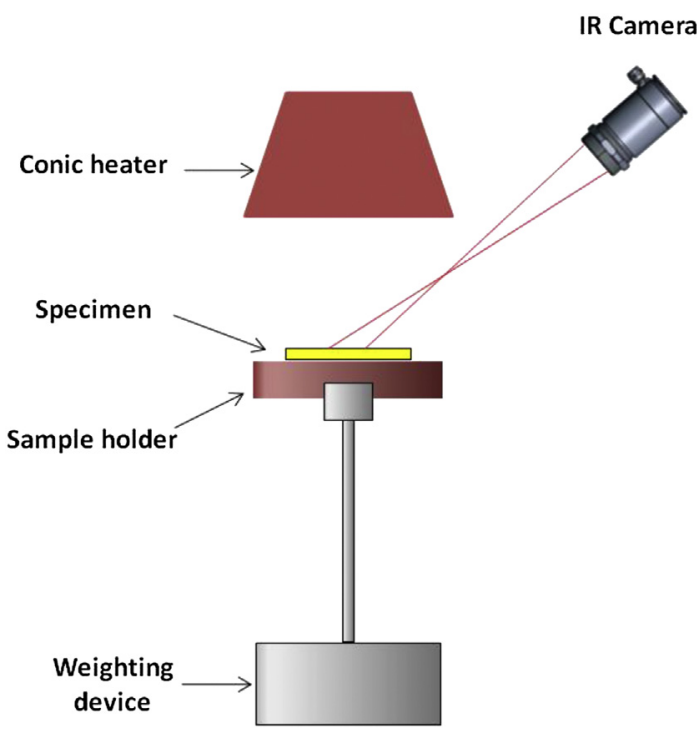

Fig. 2. Scheme of cone calorimeter test equipped with IR camera.

The temperatures lower than $125{ }^{\circ} \mathrm{C}$ were not recorded. The apparatus is presented in Fig. 2. It is noteworthy that temperature measured by IR camera is not exact if the emissivity of the material is not equal to 1 . Nevertheless, many polymers (including PP) have an emissivity close to 1 and then the uncertainty on measurement remains limited. Lyon reported a surface absorptivity between 0.8 and 0.9 for PP according to the radiant source (black body or flames) [38].

\subsection{Phosphonate grafted silica}

The amount of SiP grafted onto the T365 and Z1165MP was first estimated by thermogravimetric analysis (TGA). The TGA results, shown in Fig. 3, evidence the surface modification of the two silicas, T365 and Z1165MP. Without any purification, both unmodified silicas have a similar behavior with a total mass loss of approximately $10 \mathrm{wt} \%$. This mass loss can be observed around $100{ }^{\circ} \mathrm{C}$ for both samples corresponding to the release of physisorbed water [39]. The TGA profile of grafted silicas Tm and $\mathrm{Zm}$ also highlighted a loss (including water and solvents residues losses) around $100{ }^{\circ} \mathrm{C}$ corresponding in that case to only $1.2 \mathrm{wt} \%$. The decrease of the water content between pure and grafted silicas is assigned to the grafting reaction modifying the surface nature.

A second mass loss for $\mathrm{Tm}$ and $\mathrm{Zm}$, of $\mathrm{ca}$. $10 \mathrm{wt} \%$ and $8 \mathrm{wt} \%$ respectively, is observed in the range $200-600^{\circ} \mathrm{C}$ with a maximum centered at $245{ }^{\circ} \mathrm{C}$ and $300{ }^{\circ} \mathrm{C}$ respectively. This mass loss can be ascribed to the decomposition of SiP grafted onto silica.

Elemental analysis reported in Table 2 points out the phosphorus content at the surface of the modified silicas. This rate around $1.4 \mathrm{wt} \%$ is equivalent for the two grafted silicas $\mathrm{Tm}$ and $\mathrm{Zm}$ but is slightly higher than the one calculated from previous TGA mass losses $\left(P_{\text {th }}\right)$. The calculation was made considering that the three ethoxy groups of SiP had been hydrolyzed and one of the resulting silanol was condensed on the silica surface. With these hypotheses, the calculated phosphorus content is ca. $1.3 \mathrm{wt} \%$ instead of ca. $1.5 \mathrm{wt} \%$ for Tm and ca. $1.0 \mathrm{wt} \%$ instead of $c a .1 .4 \mathrm{wt} \%$ for $\mathrm{Zm}$. These small differences could be due to the uncertainties of measurement and could suggest that SiP is not only present on the surface of silica but also exists in the form of condensed species.

The presence of various SiP chemical species at the silica surface has been highlighted by ${ }^{29} \mathrm{Si}$ and ${ }^{31} \mathrm{P}$ solid NMR. The spectra of silica T365 and grafted silica Tm are respectively depicted in Figs. 4 and 5. 


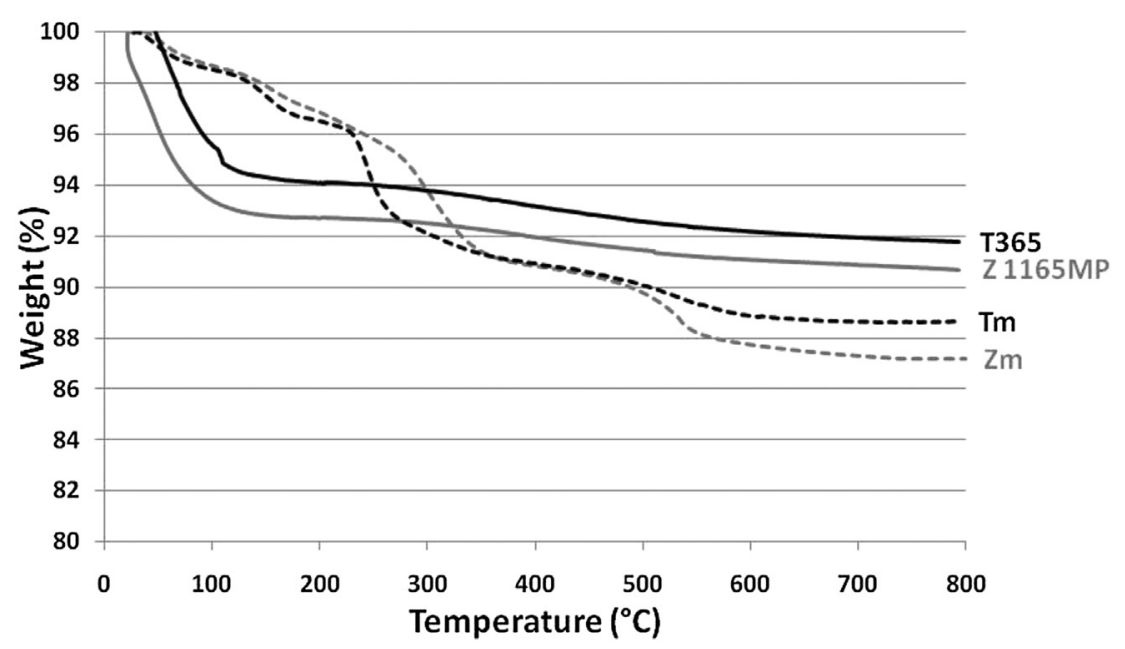

Fig. 3. TGA curves for silicas T365, Z1165MP, grafted silica Tm and grafted silica Zm respectively under air.

Table 2

Results of elemental analysis for grafted silica Tm and Zm.

\begin{tabular}{lllll}
\hline & $\mathrm{Si}(\% \mathrm{wt})$ & $\mathrm{P}(\% \mathrm{wt})$ & $\mathrm{P} / \mathrm{Si}$ & $\mathrm{P}_{\mathrm{th}}{ }^{\mathrm{a}}$ (\%wt) \\
\hline $\mathrm{Tm}$ & 39.4 & 1.5 & 0.038 & 1.3 \\
$\mathrm{Zm}$ & 39.3 & 1.4 & 0.036 & 1.0 \\
\hline
\end{tabular}

${ }^{\text {a }}$ Calculated considering TGA results.
The two ${ }^{29} \mathrm{Si}$ HPDEC-MAS NMR spectra (Fig. 4) exhibit two characteristics peaks of the structural organization of $\mathrm{SiO}_{2}$ around $-104 \mathrm{ppm}$ and $-113 \mathrm{ppm}$, corresponding to the condensed species $\mathrm{Q}^{3}\left((\mathrm{Si}-\mathrm{O})_{3}-\mathrm{Si}-\mathrm{OR}\right)$ and $\mathrm{Q}^{4}\left((\mathrm{Si}-\mathrm{O})_{4}-\mathrm{Si}\right)$ respectively [40-42]. On ${ }^{29} \mathrm{Si}$ NMR spectrum of the Tm depicted in Fig. $4 \mathrm{~b}$ two additional signals at -60 and $-69 \mathrm{ppm}$ are detected. They are

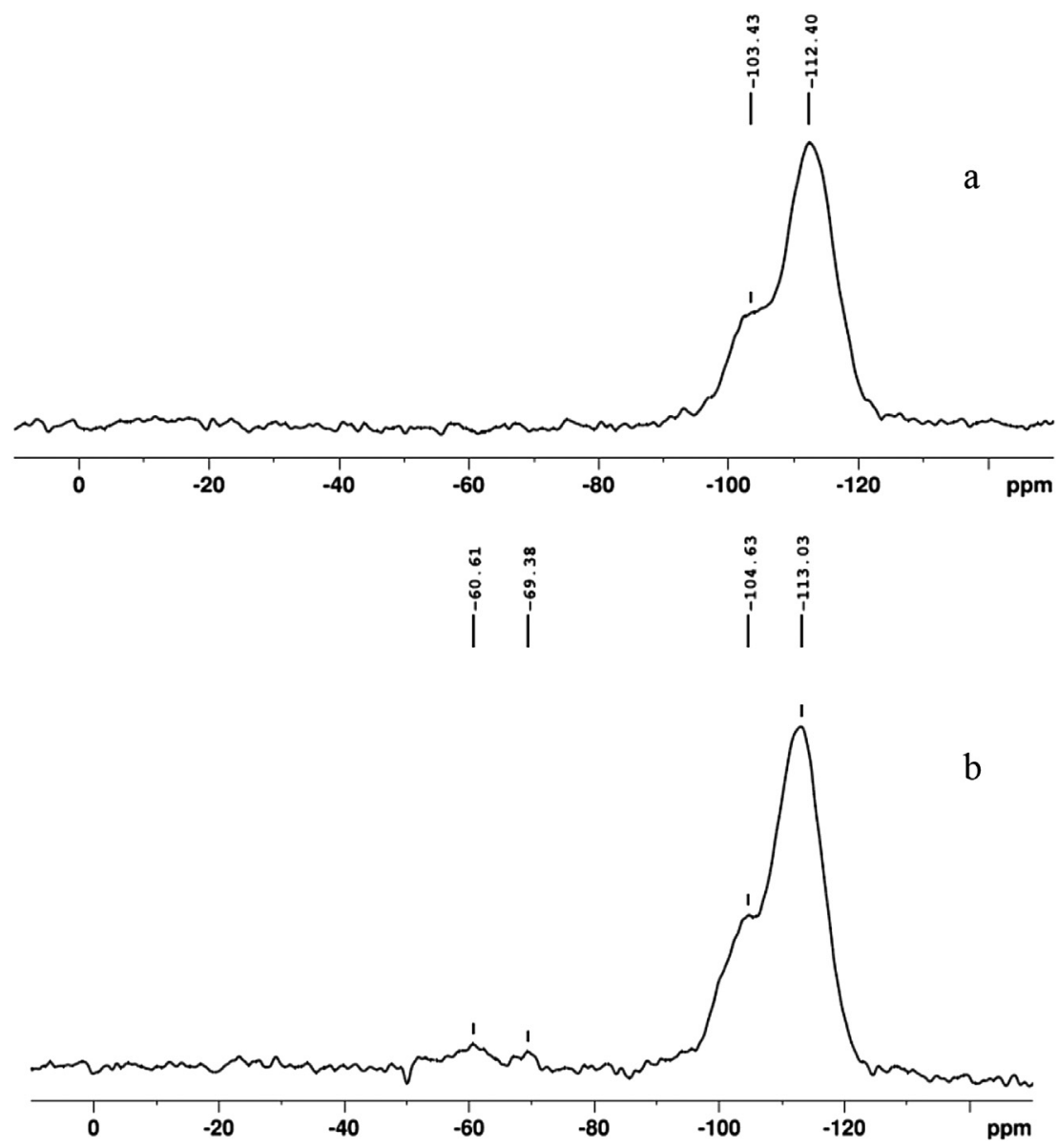

Fig. 4. ${ }^{29}$ Si MAS NMR spectrum of (a) pure silica T365 and (b) grafted silica Tm. 


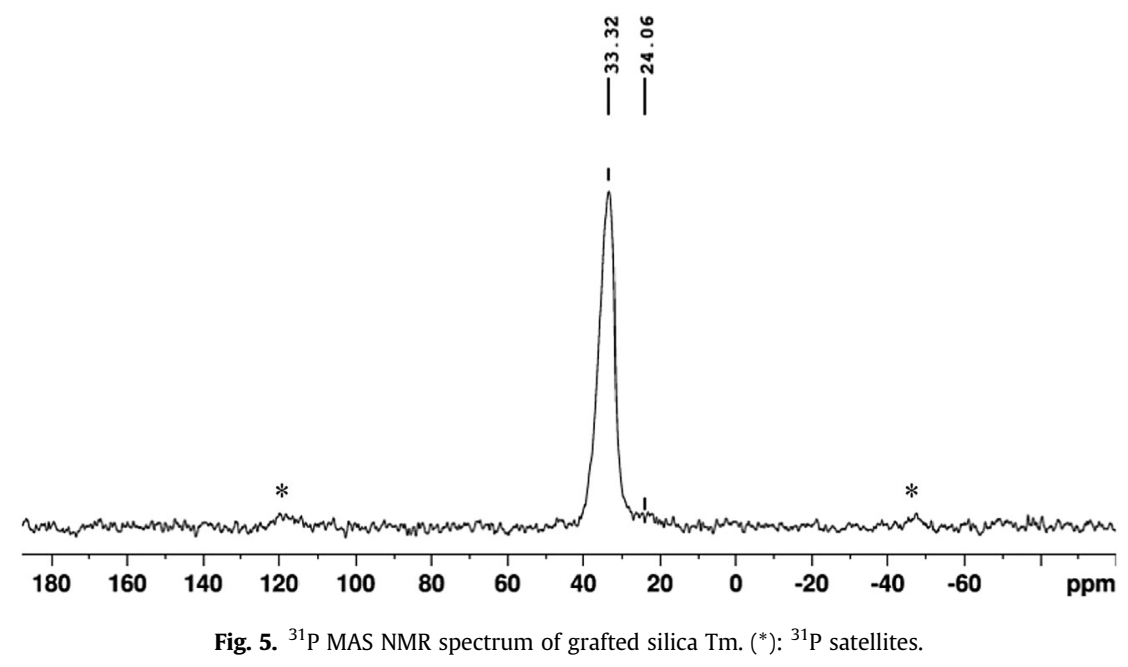

assigned to the condensed species derived from SiP, $\mathrm{T}^{2}$ $\left((\mathrm{Si}-\mathrm{O})_{2}-\mathrm{Si}(\mathrm{OR})-\mathrm{R}\right)$ and $\mathrm{T}^{3}\left((\mathrm{Si}-\mathrm{O})_{3}-\mathrm{Si}-\mathrm{R}\right)$ respectively [43]. Their low intensities are also in agreement with the low SiP concentration grafted onto the silica.

${ }^{31} \mathrm{P}$ HPDEC-MAS NMR spectrum recorded on the grafted silica (Fig. 5) allows assessing the stability of the phosphonate function. Indeed, two peaks at $33 \mathrm{ppm}$ and $24 \mathrm{ppm}$ are observed. The first peak is characteristic of the phosphonate function of the SiP precursor. The second small peak is assigned to the condensed species of the phosphonate function of SiP from literature data $[43,44]$. It was explained that when $\mathrm{PO}(\mathrm{OH})_{3}$ condenses to form $\mathrm{PO}(\mathrm{OH})_{2}-\mathrm{O}$ $\mathrm{PO}(\mathrm{OH})_{2}$, a shift in the ${ }^{31} \mathrm{P}$ peak position from $-11 \mathrm{ppm}$ to $24 \mathrm{ppm}$ is observed. Similar results (not shown here) are observed for $\mathrm{Z} 1165 \mathrm{MP}$ and $\mathrm{Zm}$.

All these results allow us to propose a scheme of the different possible interactions between SiP and silica as shown in Fig. 6. This scheme is close to that proposed by Alongi et al. [45].

The influence of the SiP grafting reaction was also evaluated through the morphology analysis by SEM. From the micrographs shown in Fig. 7a and c no difference between T365 and Tm can be observed. The grafting process did not change the aspect of the T365 silica particles whose size is about $3 \mu \mathrm{m}$. On the contrary, Z1165MP and Zm morphologies are different. As shown in Fig. 7b and d, Z1165MP silica appears as micropearls whereas $\mathrm{Zm}$ is formed of non spherical microparticles. The difference observed between $\mathrm{Z} 1165 \mathrm{MP}$ and $\mathrm{Zm}$ can be explained by the grafting process. Indeed, the stirring applied to Z1165MP during the SiP grafting allows breaking the micropearls to form non spherical microparticles with an average size of around $50 \mu \mathrm{m}$ instead of $250 \mu \mathrm{m}$ for Z1165MP (Fig. 7d and b).

\section{Results and discussion}

\subsection{Analysis of PP/silica composites morphology}

The morphologies of PP composites were characterized by SEM as shown in Fig. 8. The observations were carried out on the surface and the cross-section of the samples. From these micrographs different degrees of dispersion can be observed. Grafted silica Tm and $\mathrm{Zm}$ are better dispersed into the PP than pure silica T365 and Z1165MP. Samples prepared with pure silica PP-T-10\% and PP-Z-10\% (Fig. 8a and b) show a non-homogeneous dispersion, presenting spherical particles with a broad size distribution from 100 to $500 \mathrm{~nm}$ for smaller particles to $5-150 \mu \mathrm{m}$ for the aggregates. The primary particles of both pure silicas seem to form a network which may be caused by hydrogen or Van der Waals bondings between particles due to silanols at the silica surface [46]. In spite of their initial different size, the final silica dispersion after shearing in the extruder leads to similar degree of dispersion due to the breaking of the Z1165MP micropearls.

On the other hand, the samples PP-Tm-10\% and PP-Zm-10\% (Fig. $8 \mathrm{c}$ and d), present a finer grafted silica dispersion in the matrix polymer. The size distribution of particles is still quite broad $(80-300 \mathrm{~nm})$ but narrower than for PP/pure silica composites. There are almost no aggregates with grafted silica. In both cases, the presence of SiP grafted onto the silica surface seems to create

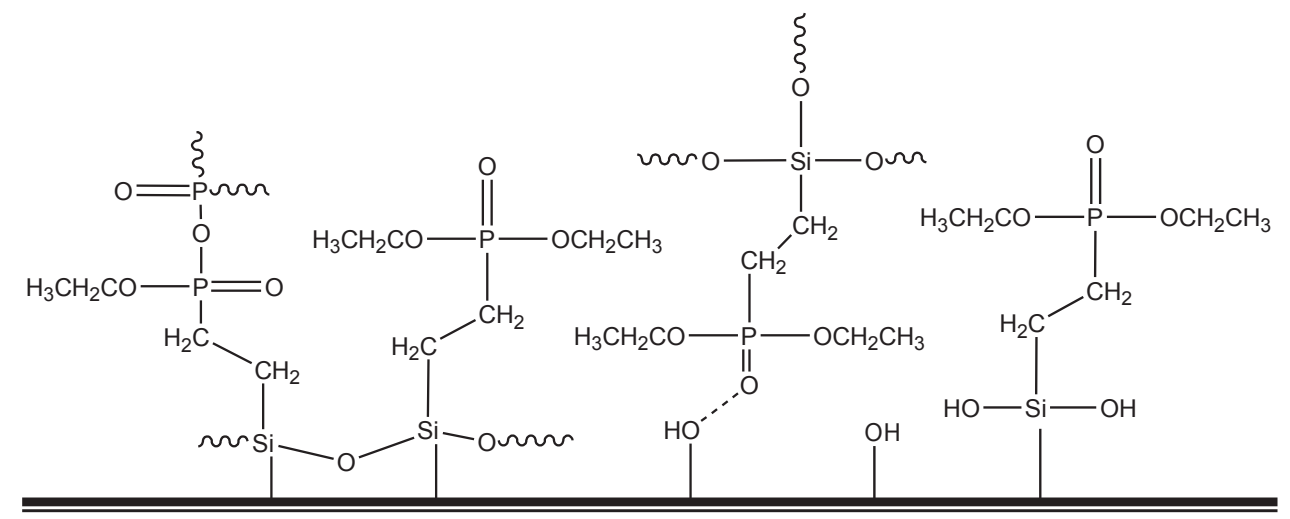

Fig. 6. Illustration of SiP grafted silica. 

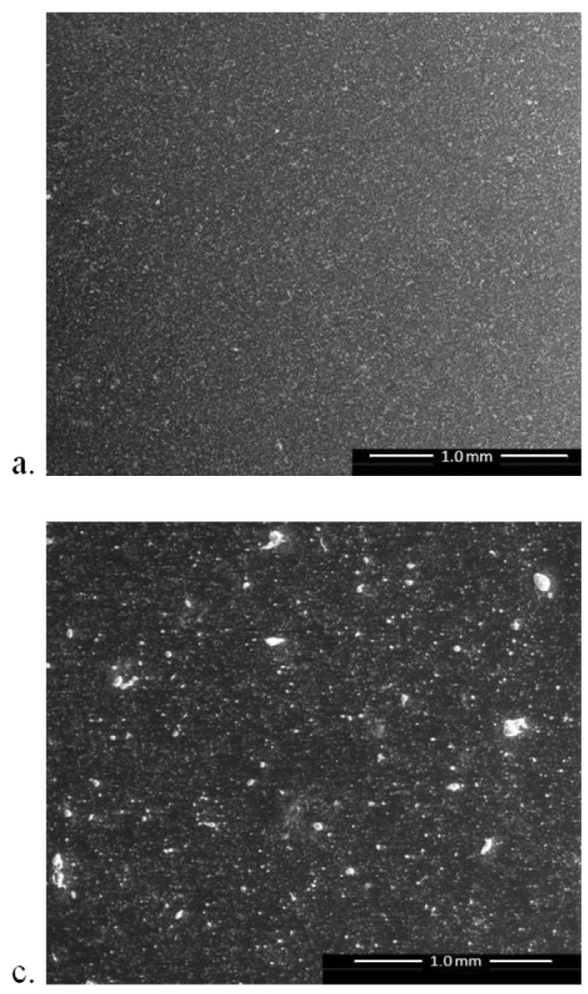

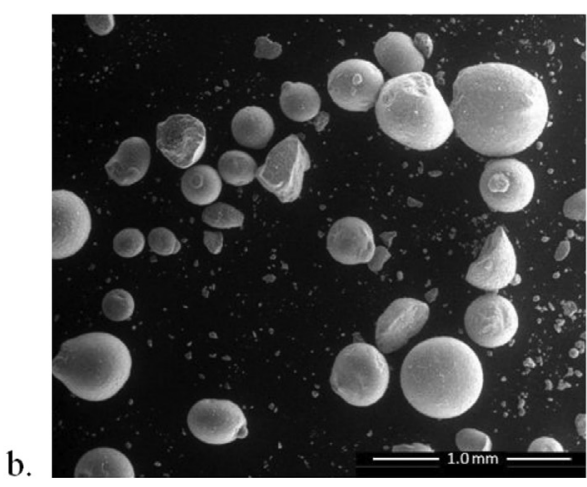

d.

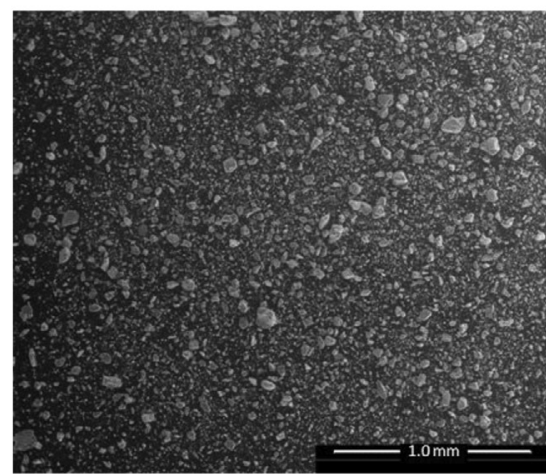

Fig. 7. SEM images of (a) T365, (b) Z1165MP, (c) Tm and (d) Zm

repulsion between particles preventing the formation of a particle network in the polymer matrix. Such a behavior was already described by Bartholome et al. [46]. They showed the influence of steric repulsion created by the polystyrene (PS) chains grafted onto fumed silica surface on the filler dispersion. When modified silica was introduced in PS matrix, there were no more inter-particle bonds thus implying a better fillers distribution than pure silica particles. Indeed, unmodified silica presented a network structure in the polymer matrix.

The elemental analysis for carbon, silicon and phosphorus elements is presented in Table 3.

It confirms that grafted silicas have been introduced in PP matrix without loss of phosphorus since the $\mathrm{P} / \mathrm{Si}$ rates are close to those measured before compounding and presented in Table 2. The final rates of phosphorus element in PP-Tm-10\% and PP-Zm-10\% are quite low and equal to $0.087 \mathrm{wt} \%$ and $0.120 \mathrm{wt} \%$ respectively. From these results, the actual rates of fillers added were calculated and were found to be lower than the theoretical value of $10 \mathrm{wt} \%$ of filler introduced in PP using these extrusion conditions, except for PP$\mathrm{Zm}-10 \%$.

Another method to characterize the morphology of composites is to study their linear viscoelastic behavior [46,47]. In the present study we have focused our discussion on the variation of the storage modulus $G^{\prime}(\omega)$ and the absolute complex viscosity $\left|\eta^{*}(\omega)\right|$ (Fig. 9). At low angular frequency, the viscosity (Fig 9A) of all composites is higher than that of pure PP. Moreover, it should be noticed that the highest viscosities are obtained for $\mathrm{PP} /$ pure silica composites. The difference of dispersion between pure silica and grafted silica (Fig. 8) influences the viscosity of the composites: the finer the silica dispersion is, the lower the viscosity is. Furthermore, as shown in Fig. 9B, the addition of fillers leads to an increase of $\mathrm{G}^{\prime}(\omega)$ in agreement with the variation of the absolute complex viscosity. This increase is more important for PP-T-10\% and PP-Z$10 \%$ (Fig. 9B, b and $\mathrm{c}$ ), whose $\mathrm{G}_{0}$ (storage modulus of the secondary plateau at low frequency) are equal to $1,6 \times 10^{3} \mathrm{~Pa}$ and $7,1 \times 10^{2}$ Pa respectively, indicating a more elastic behavior for these composites. Indeed, the neat silica particles form a network because of the hydrogen bondings between silanols at the silica surface, which leads to the increase of the viscosity of the composite [24]. Such a rheological behavior is in accordance with the SEM observations. As shown by Bartholome et al. [46], modifying the surface of fumed silica by PS grafting has an effect on the dispersion in the polymer matrix which influences the viscoelastic behavior. In their study, nanocomposites prepared by adding $5 \mathrm{vol} \%$ of unmodified fillers in PS shows a predominant elastic character with a secondary plateau at low frequencies $\left(G_{0} \approx 3 \times 10^{4} \mathrm{~Pa}\right)$. This plateau is characteristic of the presence of a network structure. For grafted silica/PS composites, this secondary elastic plateau considerably decreases down to disappear by increasing the grafting density of PS-modified silica. As said above, the steric repulsion between grafted-silica particles leads to the breakdown of the network structure.

\subsection{Thermal and fire-retardant behavior}

\subsubsection{Thermal behavior}

Thermogravimetric analyses under nitrogen and air of the different composites were carried out to determine the effect of the addition of pure and grafted silicas on the thermal stability of PP. The TGA results are presented in Fig. 10.

The thermal degradation of PP and its composites under nitrogen (Fig. 10A) takes place through one-step process corresponding to the well described random $\mathrm{C}-\mathrm{C}$ bond scission mechanism $[11,48]$ and occurs in a range of temperatures between $375^{\circ} \mathrm{C}$ and $500{ }^{\circ} \mathrm{C}$. The initial pure PP decomposition temperature corresponding to a $2 \mathrm{wt} \%$ weight loss is about $385{ }^{\circ} \mathrm{C}$ whereas this temperature is slightly shifted to higher temperature for PP-T-10\% and PP-Z-10\% (Fig. 10b and c), $395^{\circ} \mathrm{C}$ and $390{ }^{\circ} \mathrm{C}$ respectively. The peak of mass 


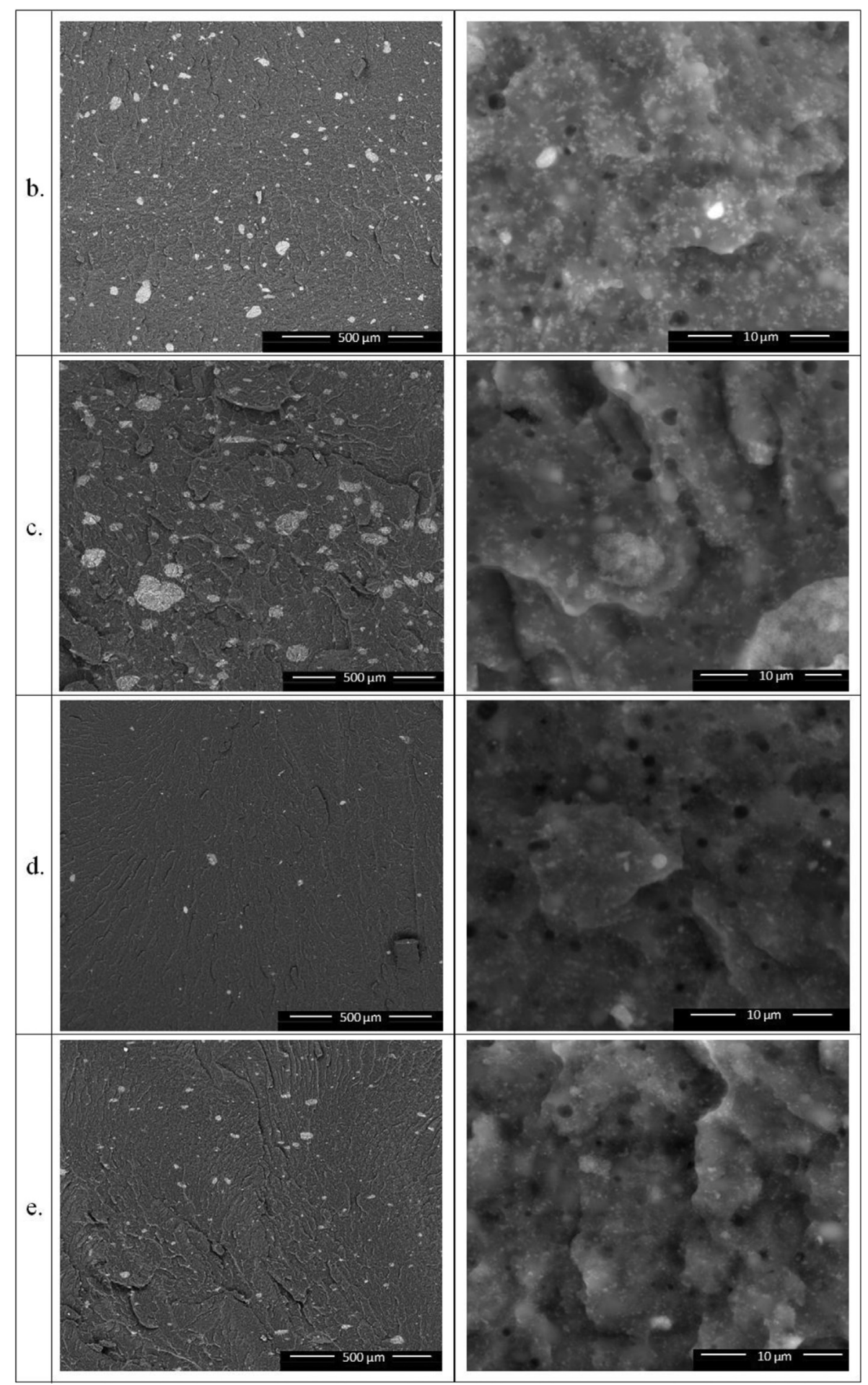

Fig. 8. SEM images of PP composites: (a) PP-T-10\%, (b) PP-Z-10\%, (c) PP-Tm-10\% and (d) PP-Zm- $10 \%$.

Table 3

Results of elemental analysis for PP composites.

\begin{tabular}{lllllc}
\hline & $\mathrm{C}(\mathrm{wt} \%)$ & $\mathrm{Si}(\mathrm{wt} \%)$ & $\mathrm{P}(\mathrm{wt} \%)$ & $\mathrm{P} / \mathrm{Si}$ & Rate of filler $^{\mathrm{a}}$ (wt\%) \\
\hline a) PP-T-10\% & 77.8 & 3.6 & 0 & 0 & 7.6 \\
b) PP-Z-10\% & 79.5 & 2.7 & 0 & 0 & 5.7 \\
c) PP-Tm-10\% & 78.9 & 3.0 & 0.087 & 0.029 & 7.7 \\
d) PP-Zm-10\% & 79.6 & 4.2 & 0.120 & 0.030 & 10.7 \\
\hline
\end{tabular}

a Calculated from Si values. loss rate (pMLR) is also shifted from $443^{\circ} \mathrm{C}$ for pure extruded PP to $454{ }^{\circ} \mathrm{C}$ and $452{ }^{\circ} \mathrm{C}$ for PP-T-10\% and PP-Z-10\% respectively. This slight increase has already been reported in the literature $[18,19,48-50]$ and is assigned to the formation of PP chains tightly bound around silica particles, thereby limiting the polymer chains mobility [24]. Other studies explain that nanofillers could act as volatile decomposition products shield [48-50].

The results obtained with composites containing grafted silicas Tm and Zm (Fig. 10d and e) are slightly different. Indeed, the 

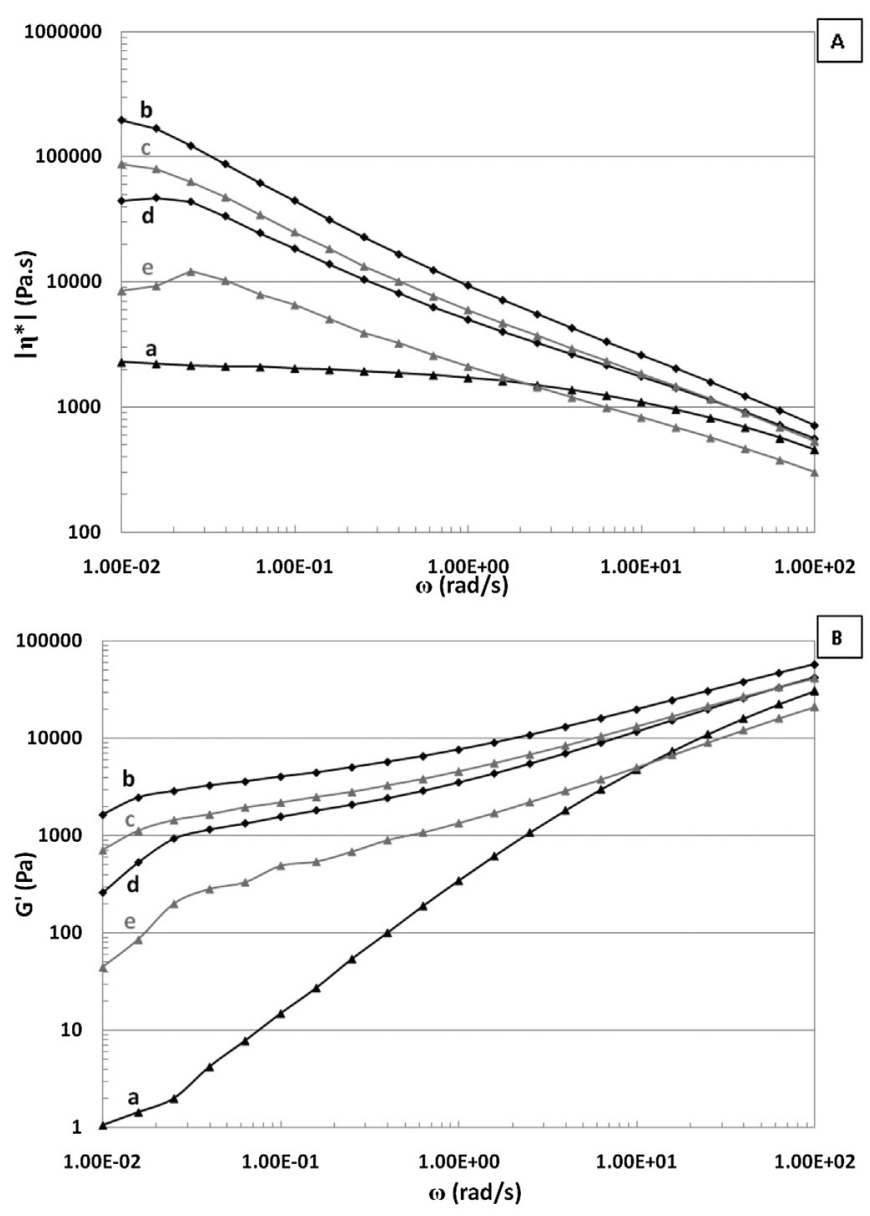

Fig. 9. Variation of complex viscosity (A) and storage modulus (B) for (a) PP, (b) PP-T10\%, (c) PP-Z-10\%, (d) PP-Tm-10\% and (e) PP-Zm-10\%.

temperature of pMLR for PP-Tm-10\% and PP-Zm-10\% increases of about $10{ }^{\circ} \mathrm{C}$ compared to pure PP but both composites start to decompose at lower temperature, $370{ }^{\circ} \mathrm{C}$ and $380{ }^{\circ} \mathrm{C}$ respectively. This very slight decrease of the initial degradation temperature may be assigned to the weak energy of $\mathrm{P}-\mathrm{C}$ and $\mathrm{P}-\mathrm{O}$ bonds [43].

Moreover it should be noted that PP decomposes completely at about $475^{\circ} \mathrm{C}$. The amount of residue for the composites is respectively $8 \mathrm{wt} \%, 8 \mathrm{wt} \%, 6.5 \mathrm{wt} \%$ and $5 \mathrm{wt} \%$ for PP-T-10\%, PP-Z-10\%, PPTm-10\% and PP-Zm-10\% which corresponds roughly to the initial loading of filler and indicates that no char was formed.

The thermo-oxidative degradation of pure PP due to peroxidation chain reaction takes place in two steps $[11,48,51]$. The first step corresponds to the main degradation (due to the formation of radicals by $\beta$-scission) and occurs between 225 and $390{ }^{\circ} \mathrm{C}$. The second step (after $400{ }^{\circ} \mathrm{C}$ ) evidences the dehydrogenation of PP radicals and the oxidation of the residue formed during the first step $[11,48]$. The PP composites also exhibit degradation in two steps. However, the addition of silica increases significantly the thermal stability of the polymer matrix under air. With about $10 \mathrm{wt}$ $\%$ of fillers, the temperature of the pMLR is shifted from $310^{\circ} \mathrm{C}$ to $\mathrm{ca}$. $380^{\circ} \mathrm{C}$ and $410^{\circ} \mathrm{C}$ for PP/pure silica composites and PP/grafted silica composites respectively. The grafted silica seems to impart better thermo-oxidative stability to the polymer matrix but the amount of char after the first step of degradation is higher for PP ( $\approx 3.8 \mathrm{wt} \%$ ) than for all composites ( $\approx 1.6 \mathrm{wt} \%$ ). The amount of residue obtained under air at $600{ }^{\circ} \mathrm{C}$ is the same than that obtained under nitrogen for all samples, which suggests that no char is formed with the addition of pure and modified silicas. In their studies, Palza et al. [18] confirm that with $5 \mathrm{wt} \%$ of spherical silica nanoparticles, the thermal degradation of PP is considerably improved under air (increase of pMLR temperature of $70^{\circ} \mathrm{C}$ ) in comparison to tests carried out under nitrogen (increase of pMLR temperature of $10^{\circ} \mathrm{C}$ ). The authors show that the thermal degradation is slightly delayed by adding a compatibilizer (PP-g-MA) $\left(\approx 10^{\circ} \mathrm{C}\right.$ and $\approx 30^{\circ} \mathrm{C}$ under inert and oxidative atmosphere respectively) which may prove that the dispersion plays a role on the thermal stability. They also postulated that such an improvement under air may be due to the high specific area of the filler $\left(\approx 70 \mathrm{~m}^{2} / \mathrm{g}\right)$ that may trap the oxidized volatile products during the degradation.

In conclusion, it must be noted that grafted silica seems to act as an efficient thermal stabilizer under oxidative condition, delaying the main degradation step of materials. Such stabilization may have at least an effect on the time to ignition of materials during cone calorimeter tests.

\subsubsection{Flame retardancy: PCFC and cone calorimeter}

To complete the thermal analysis, the flammability of previous materials was analyzed using PCFC. The Heat Release Rate (HRR) curves for the composites are shown in Fig. 11.

A slight decrease of peak HRR (pHRR) for all types of silica based composites is observed. Despite the presence of phosphorus (in very small amounts) in PP-Tm-10\% and PP-Zm-10\% (0.087 wt\% and $0.12 \mathrm{wt} \%$ respectively measured by elemental analysis), the $\mathrm{PP} /$ pure silica composites PP-T-10\% and PP-Z-10\% (Fig. 11b and c) show a slightly higher reduction of pHRR. Indeed composites containing grafted silica (Fig. 11d and e) exhibit a 15\% decrease of pHRR whereas the composites PP-T-10\% and PP-Z-10\% show a $20 \%$ decrease compared to pure PP. With regards to the THR (results not shown here) the maximum decrease of $13 \%$ is obtained for the composite containing non-grafted Z1165MP. These results point out that the decrease of pHRR and THR is mainly due to the substitution of about $10 \mathrm{wt} \%$ of the organic polymer matrix by roughly $10 \mathrm{wt} \%$ of fillers without creating any char which is in accordance with TGA results. It must be noticed that the temperature for which pHRR reaches a maximum, is at least $5{ }^{\circ} \mathrm{C}$ higher for PP composites than for pure PP. These results are also in accordance with the results observed in TGA (Fig. 10).

It is known that PCFC test does not take into account some effects such as barrier effect since pyrolysis is carried out on mg-scale sample [52-54]. Therefore, to evaluate the influence of physical effects on the fire properties tests were also performed on bigger samples (about $50 \mathrm{~g}$ ) using a cone calorimeter. The results are shown in Table 4 and in Fig. 12.

As shown in Fig. 12, the addition of pure silica or grafted silica in PP leads to different combustion behaviors compared to neat PP. For pure PP, a sharp HRR curve appears in the 30-300 s range with a high pHRR around $1200 \mathrm{~kW} / \mathrm{m}^{2}$. The dispersion of less than $10 \mathrm{wt}$ $\%$ of grafted silica does not induce strong variations in time to ignition and slightly decreases the pHRR whereas the addition of pure silica in PP presents another trend: a flattening of the HRR curves (b and c) with a significant decrease of TTI (from 30 to $20 \mathrm{~s}$ approximately) can be observed in Fig. 12. This evolution is not in agreement with TGA curves which show an increase of the thermal oxidative stability of composites. This obvious change of TTI between pure PP and the composites containing pure silica was already observed in the literature $[32,55,56]$ and may be assigned to a change in thermal radiative properties of the polymer. The introduction of additives such as inorganic nanoclays or carbon nanotubes can change the transmitted heat and the convective flow through the material and thus change the ignition time. Moreover, Fina et al. show that in the case of nanoclays, nanoparticles may catalyze the formation of gases from the polymer degradation [56]. 

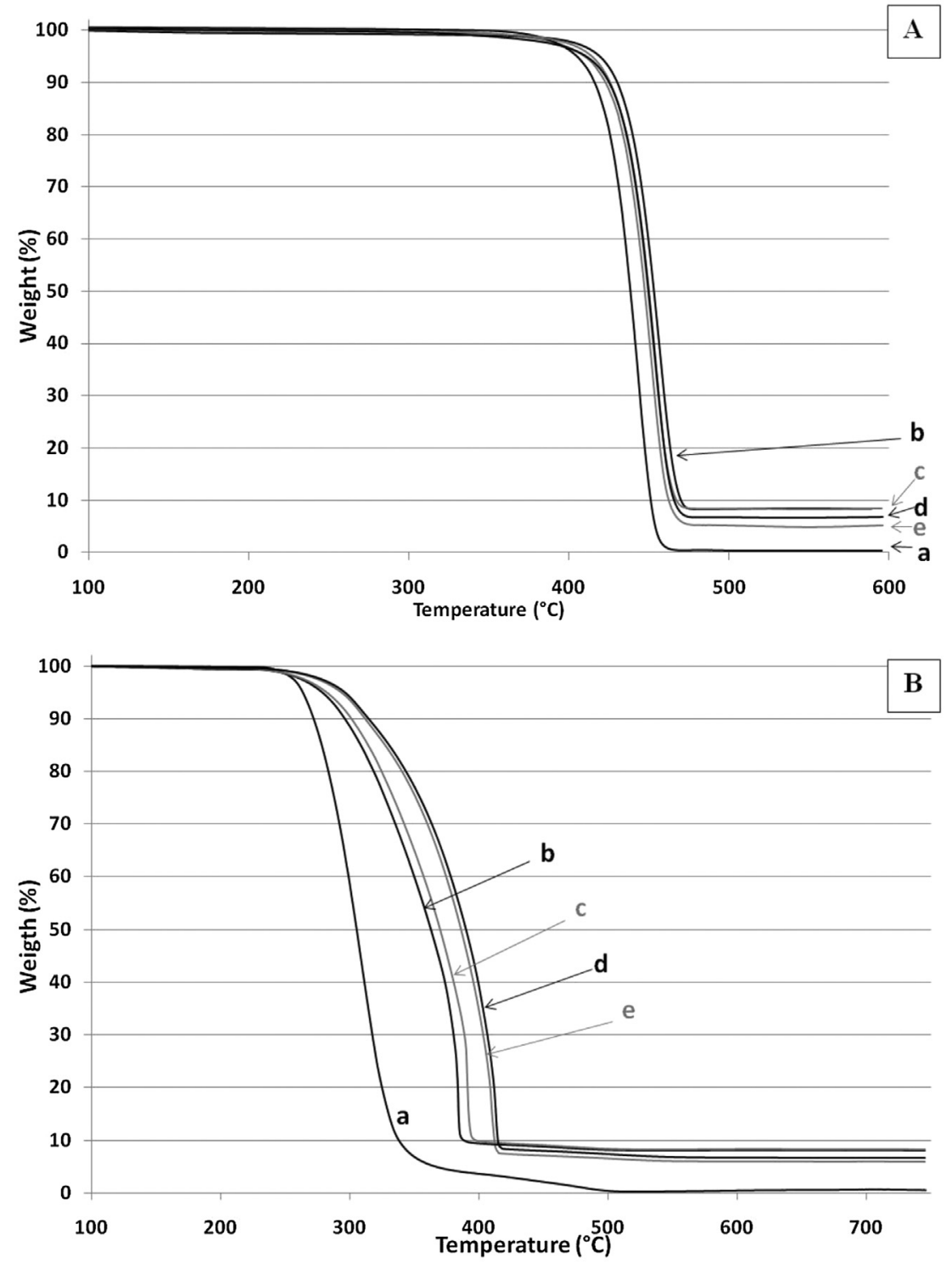

Fig. 10. TGA curves under nitrogen (A) and under air (B) for (a) PP, (b) PP-T-10\%, (c) PP-Z-10\%, (d) PP-Tm-10\% and (e) PP-Zm-10\%.

As shown in Table 4, when pure silica was added to PP, the TTI presents a $10 \mathrm{~s}$ decrease whereas the TTI of PP/grafted silica composites is unchanged compared to that of pure PP. In order to explain these results, cone calorimeter tests were performed under an irradiance of $15 \mathrm{~kW} / \mathrm{m}^{2}$ and using an IR camera to measure the surface temperature of samples during the experiment. This study is based on the hypothesis that phenomena inducing ignition at $15 \mathrm{~kW} / \mathrm{m}^{2}$ and $50 \mathrm{~kW} / \mathrm{m}^{2}$ are the same. Temperatures at the upper surface of neat PP and PP-Z-10\% are presented in Fig. 13. The temperature increase is the same for both samples up to $160{ }^{\circ} \mathrm{C}$, which corresponds to the melting point of PP. Above $160^{\circ} \mathrm{C}$, two distinct behaviors can be described: for PP-Z-10\% (TTI at $50 \mathrm{~kW} / \mathrm{m}^{2}$ equals to $18 \mathrm{~s}$ ), the heating is faster than for PP (TTI at $50 \mathrm{~kW} / \mathrm{m}^{2}$ equals to $31 \mathrm{~s}$ ). Moreover PP does not ignite under an irradiance of $15 \mathrm{~kW} / \mathrm{m}^{2}$ after $300 \mathrm{~s}$ contrary to PP-Z-10\% (TTI at $15 \mathrm{~kW} / \mathrm{m}^{2}$ approximately equals to $150 \mathrm{~s}$ ). This heating acceleration is correlated with the appearance of bubbling phenomenon. Oztekin et al. have already observed the effect of bubbles formation on the TTI of wet poly(aryl ether ether ketone) (PEEK) [57]. After the PEEK melting, bubbles appeared due to water trapped in the polymer. Such bubbles have an influence on thermal and optical properties since they lead to an increase of heat absorption at the upper surface and so lead to an early ignition. Thus TTI of dry PEEK under $50 \mathrm{~kW} / \mathrm{m}^{2}(207 \mathrm{~s})$ is about twice higher than the wet PEEK one. This phenomenon was also observed for all composites (not presented here): appearance of bubbling for composites having the shortest TTI (at 15 and $50 \mathrm{~kW} / \mathrm{m}^{2}$ ), while no bubbles are observed for composites having the longest TTI. This heating acceleration could in principle be explained by other phenomena as a change of emissivity or heat absorption (for example due to the melting of crystalline domains). Nevertheless, there would be no reason to observe such a change only for some composites. Moreover, the correlation between bubbling and heating acceleration is systematic. We can assume that bubbling is actually responsible for the early ignition of some composites.

The pHRR is reduced when the fillers are added to the polymer and the observed decrease is more significant than those obtained using PCFC (the reduction is also more important for composites containing pure silica, PP-T-10\% and PP-Z-10\% shown in Fig. 12b and c, than for the other composites). It is interesting to note that for 


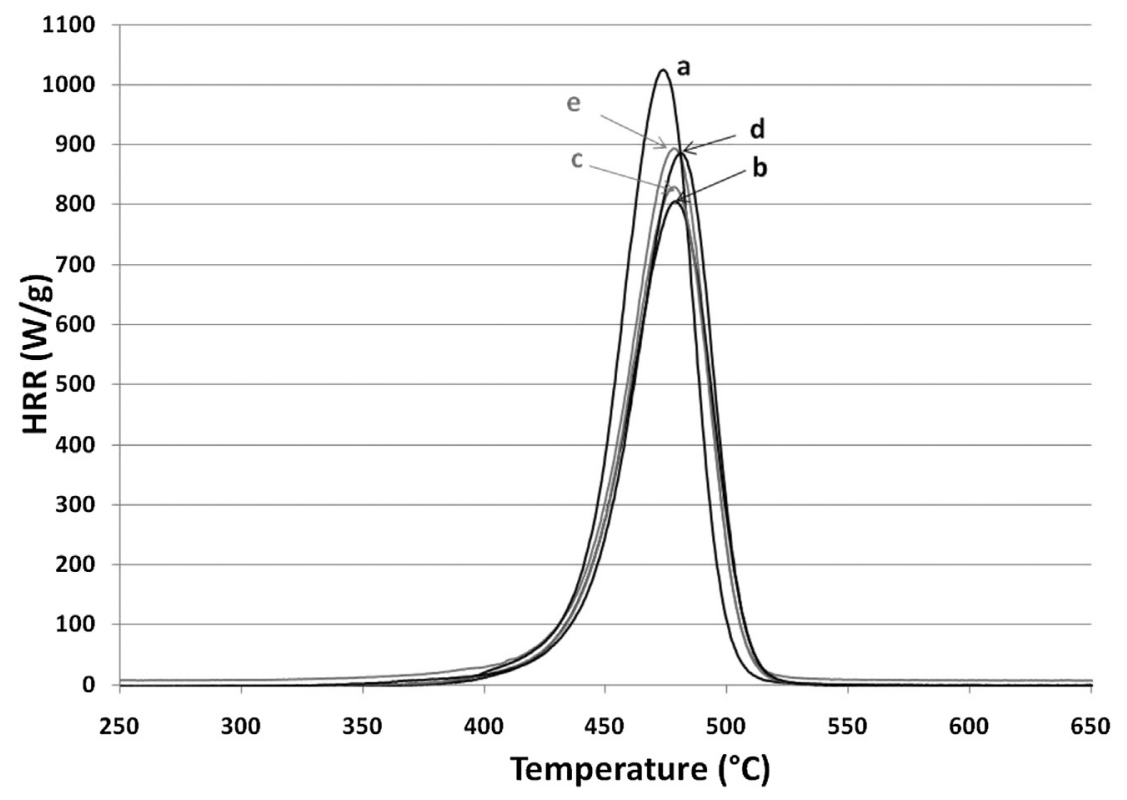

Fig. 11. PCFC curves for (a) PP, (b) PP-T-10\%, (c) PP-Z-10\%, (d) PP-Tm-10\% and (e) PP-Zm-10\%.

Table 4

Cone calorimeter results for PP composites.

\begin{tabular}{|c|c|c|c|c|c|}
\hline & TTI (s) & $\mathrm{pHRR}\left(\mathrm{kW} / \mathrm{m}^{2}\right)$ & THR (kJ/g) & Residual mass (\%) & $\mathrm{EHC}(\mathrm{kJ} / \mathrm{g})$ \\
\hline a) PP & 31 & 1214 & 40.2 & 0.0 & 40.3 \\
\hline b) $\mathrm{PP}-\mathrm{T}-10 \%$ & 22 & 662 & 37.4 & 6.6 & 40.0 \\
\hline c) $P P-Z-10 \%$ & 18 & 607 & 37.2 & 7.4 & 40.1 \\
\hline d) PP-Tm-10\% & 29 & 843 & 38.9 & 5.6 & 41.2 \\
\hline e) $P P-Z m-10 \%$ & 30 & 856 & 38.5 & 4.9 & 40.5 \\
\hline
\end{tabular}

less than $10 \mathrm{wt} \%$ of pure silica, the pHRR is two times lower with about $607 \mathrm{~kW} / \mathrm{m}^{2}$ compared to $c a .1214 \mathrm{~kW} / \mathrm{m}^{2}$ for the pure PP, which was not expected since silica is considered as an inert additive [58]. These results are in accordance with the tendency observed by Kashiwagi et al. when 10 wt\% of different types of silica are added in PP [24]. The curves d and e in Fig. 12 show that the

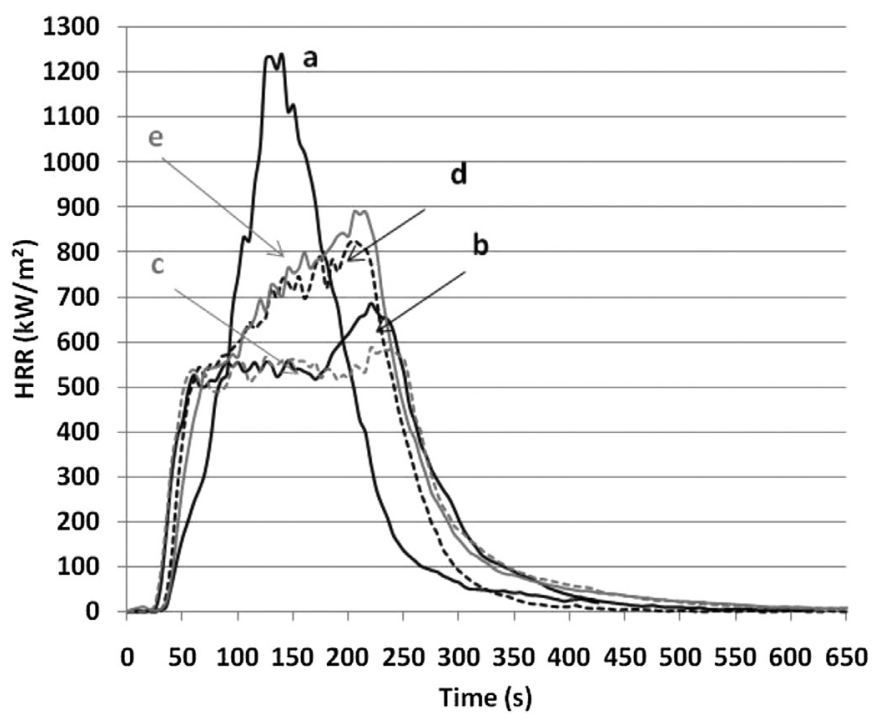

Fig. 12. Cone calorimeter curves for (a) PP, (b) PP-T-10\%, (c) PP-Z-10\%, (d) PP-Tm-10\% and (e) PP-Zm-10\%. small amount of phosphorus in PP-Tm-10\% and PP-Zm-10\% does not favorably influence the values of pHRR, which, with $c a .843$ and $856 \mathrm{~kW} / \mathrm{m}^{2}$ respectively, are higher than those of $\mathrm{PP} /$ pure silica composites.

The Effective Heat of Combustion (EHC) is an important parameter to understand how the flame retardant acts. As presented in Table 4, the EHC is almost the same for all samples. These results indicate that the pHRR decrease is only due to physical effect in condensed phase [24]. The very small amount of phosphorus in $\mathrm{PP} /$ grafted silica composites does not allow promoting a flame inhibition effect in the gas phase.

It must be noticed that the residual amount after the flame out is about $6.5 \mathrm{wt} \%$ for PP/pure silica composites and $5.5 \mathrm{wt} \%$ for composites containing grafted silica. These amounts are equivalent to those measured by TGA and confirm that none of these composites are forming a char when burning. Table 4 also shows the THR values for all materials. The results highlight that the THR decrease is higher for PP containing $10 \mathrm{wt} \%$ of pure silica T365 and Z1165MP than for PP-Tm-10\% and PP-Zm-10\% despite the presence of phosphorus. The reduction of THR is in proportion to the filler content measured by TGA, and the phosphorus agent does not promote a significant amount of char. Indeed, it is well known that PP is a noncharring polymer. That's the reason why, the common concentrations of flame retardant system containing phosphorus additives are at least $20 \mathrm{wt} \%$ [11], i.e. more than $1 \mathrm{wt} \%$ of phosphorus element in the polymer matrix (10 times more than in PP-Tm-10\% and PP$\mathrm{Zm}-10 \%$ ). With this level, the phosphorus additive can be a source of char itself (depending of the type of additive) and is often used in $\mathrm{PP}$ in synergy with other additives to act as an intumescent system $[4,11,59]$. 


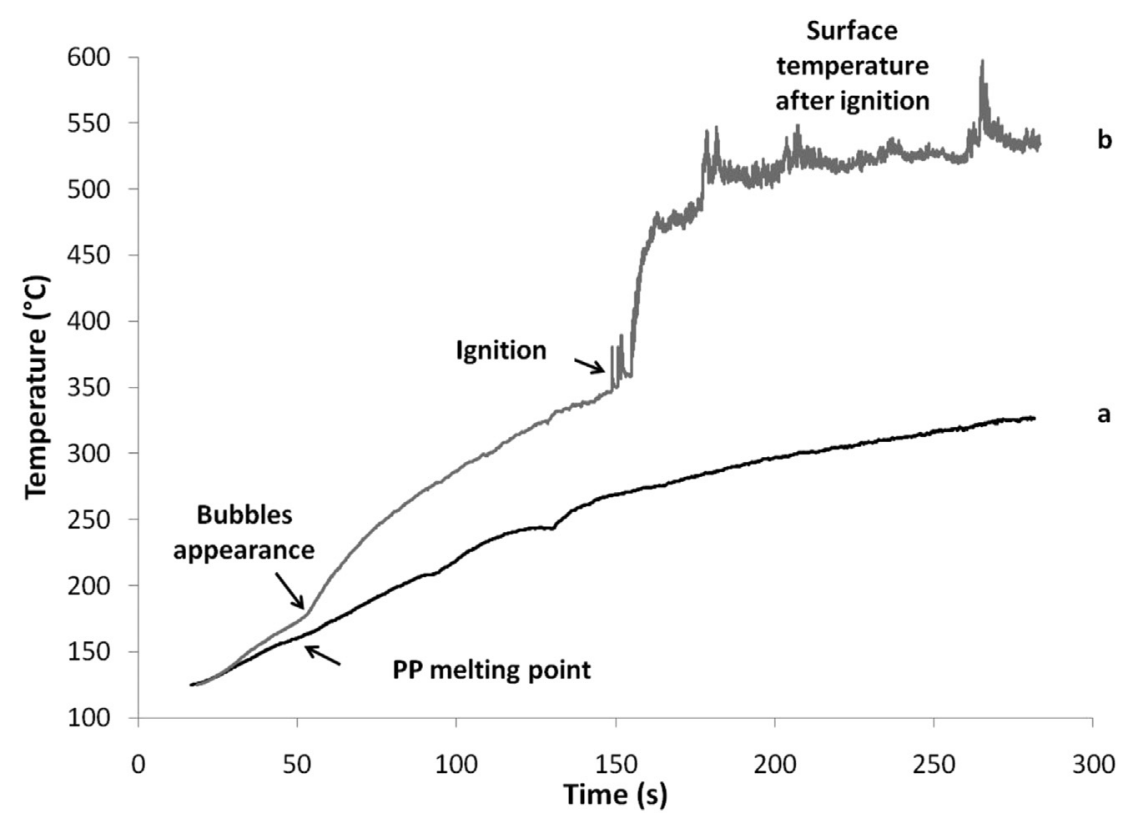

Fig. 13. Temperature of the upper surface for (a) PP and (b) PP-Z-10\%.

As shown from the pictures in Fig. 14 and from the results in Table 4, PP burns without forming any residue while the burning of composites leads to the formation of small islets-like residue. It must be noticed a difference between the size of the islets formed with pure and grafted silica. The islets formed with pure silica T365 and Z1165MP are bigger than those formed with the corresponding grafted silicas $\mathrm{Tm}$ and $\mathrm{Zm}$. Moreover the residues formed with pure silica are white whereas those formed with $\mathrm{Tm}$ and $\mathrm{Zm}$ presented black traces at their surface indicating a slight action of phosphorus in the condensed phase. Nevertheless, the value of the residual mass is almost the same as that observed in TGA analysis, indicating that there is no significant charring. The formation of such islets has already been observed in literature [24-26]. Such an organization of fillers allows creating a barrier effect in the condensed phase. Therefore this layer allows limiting mass and heat transfer between the flame and the material [24,25] which is usually the case for clay nanocomposites [60]. Nevertheless, this specific organization (discontinuous islets) is less efficient than when the filler layer completely covers the surface.

To evaluate the barrier effect in PP, results obtained using PCFC and cone calorimeter were compared [31,52,54]. The method consists in plotting the two parameters $\mathrm{R} 1$ versus $\mathrm{R} 2$, which are defined as the ratio between pHRR of the composite and PHRR of the pure polymer in PCFC and in cone calorimeter respectively (Equations (1) and (2)). The more the plotted points are above the dotted line $\mathrm{R} 1=\mathrm{R} 2$ (i.e. $\mathrm{R} 1>>\mathrm{R} 2$ ), the higher the barrier effect is.

$R 1=\frac{p H R R(\text { composite }) \text { in PCFC }}{p H R R(P P) \text { in PCFC }}$

$R 2=\frac{p H R R(\text { composite }) \text { in cone calorimeter }}{p H R R(P P) \text { in cone calorimeter }}$

It is clear from Fig. 15 that the improvement of the flame retardancy observed for all PP composites is due to the barrier effect since all points are shifted from the line R1 = R2. However, it must be noticed that the barrier effect is more important for PP/ pure silica composites, PP-T-10\% and PP-Z-10\% (Fig. 15b and c). These results confirm that for composites containing pure silica
T365 and Z1165MP, the physical barrier effect is more efficient than for PP-Tm-10\% and PP-Zm-10\%.

\subsection{Relationship between viscosity and fire behavior}

As discussed above, the presence of silica improves the fire behavior of PP thanks to physical mechanism. Kashiwagi et al. [24-26,30] have already reported that the viscosity of materials has an effect on fire behavior. Their works reported that an increase of the polymer melt viscosity by addition of large surface area or low density silica, leads to a faster accumulation of the spherical fillers at the surface of the composite during the degradation. This implies a higher reduction of mass loss rate and therefore an improvement of fire behavior by physical effects [24]. In another study comparing the fire behavior of different polymethymethacrylate (PMMA)/silica composites the authors demonstrated that for the most viscous composite (high molecular mass PMMA containing $10 \mathrm{wt} \%$ of silica gel) the bubbling is less important than for less viscous composites, which allows the accumulation of the fillers near the surface of the sample and therefore the improvement of fire properties [25].

In order to understand the difference of combustion behavior between composites containing pure silica and composites containing grafted silica, rheological properties (Fig. 9) were compared with cone calorimeter results (Table 4).

It must be noticed that regarding the cone calorimeter results, the higher the viscosity is, the lower is the pHRR. To reveal this behavior, the reduced pHRR were plotted versus the reduced $\mathrm{G}^{\prime}$ for PP filled with silica (Fig. 16). In the same manner as Batistella et al. [31], the reduced pHRR and $\mathrm{G}^{\prime}$ are calculated by the ratio between composite and pure PP. Rheological measurements were recorded at $200{ }^{\circ} \mathrm{C}$, and $\mathrm{G}^{\prime}$ values were taken at low frequency $(0.01 \mathrm{rad} / \mathrm{s})$. These conditions differ from those observed in a cone calorimeter test where a temperature gradient and hence a viscosity gradient exist. However, we suppose that at this temperature and this frequency the hierarchy of measured viscosities is qualitatively similar to the hierarchy of rheological behavior of the materials during cone calorimeter test. Fig. 16 highlights that for approximately the same filler content in PP, the reduced pHRR decreases faster from 1 to 0.7 when storage modulus increases from 1 to 400 to reach a 


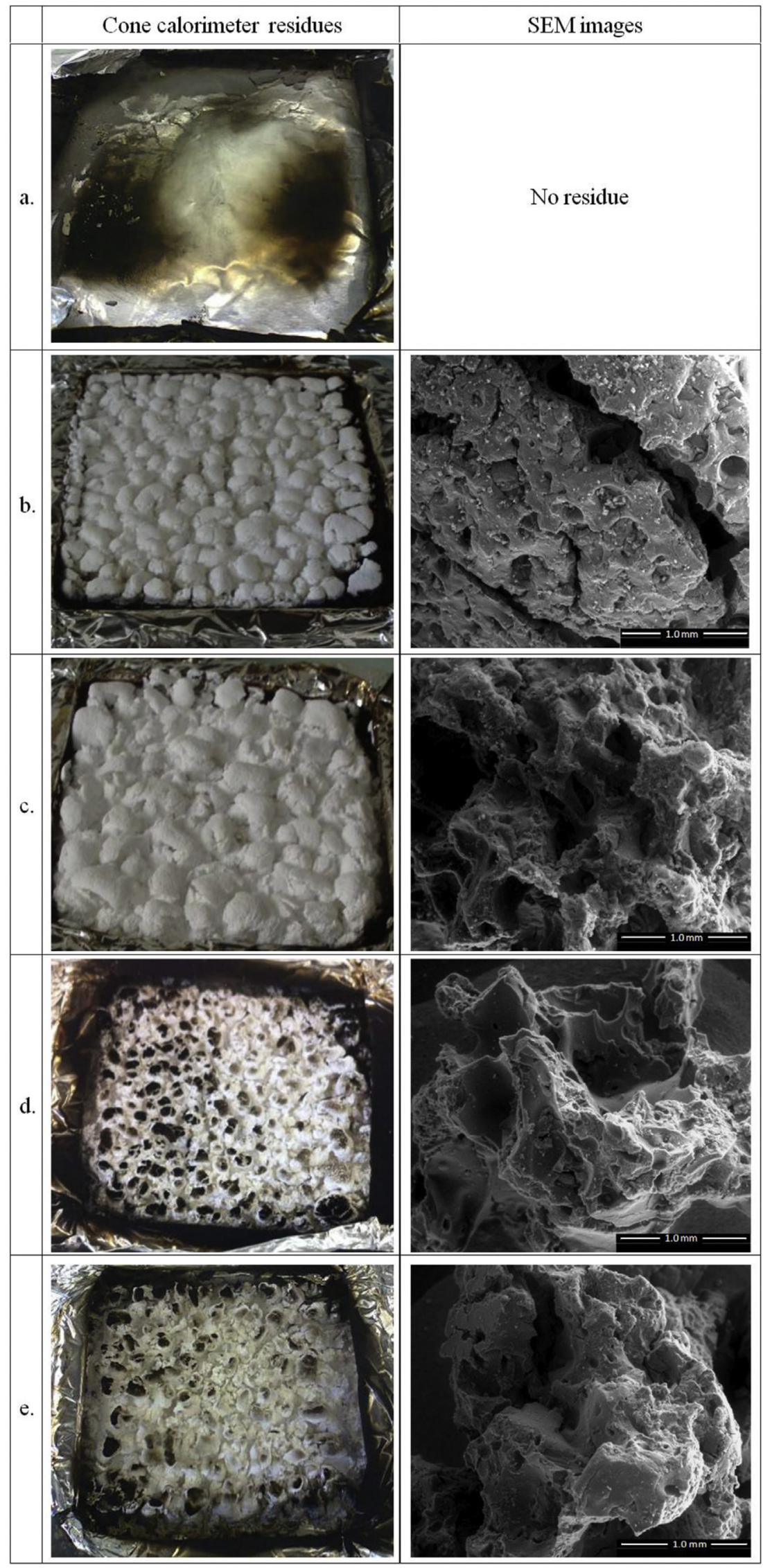

Fig. 14. Cone calorimeter residues and corresponding SEM micrographs for (a) PP, (b) PP-T-10\%, (c) PP-Z-10\%, (d) PP-Tm-10\% and (e) PP-Zm-10\%. 


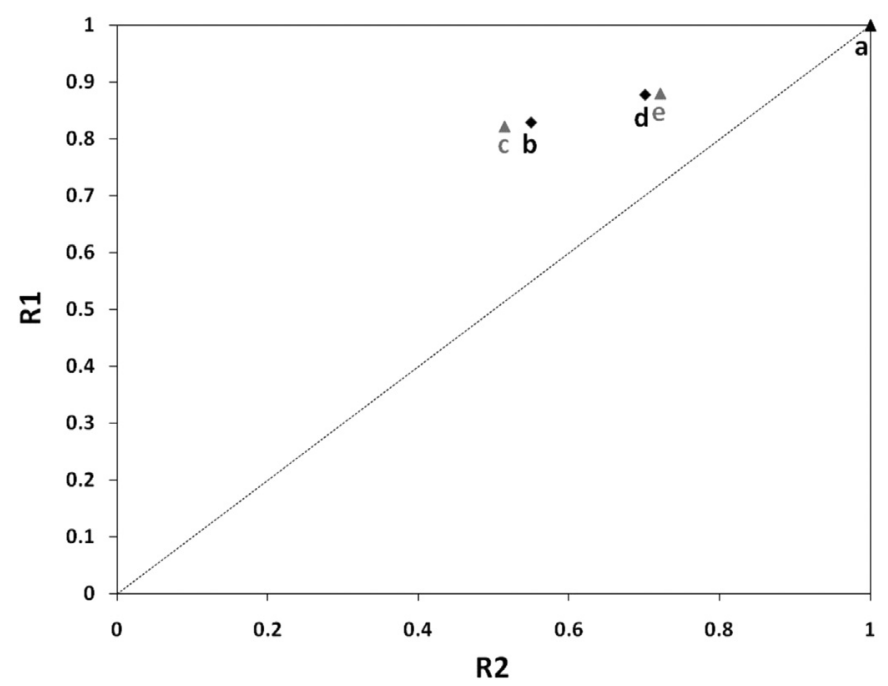

Fig. 15. R1 vs R2 plots for (a) PP, (b) PP-T-10\%, (c) PP-Z-10\%, (d) PP-Tm-10\% and (e) PP$\mathrm{Zm}-10 \%$.

plateau at about 0.5 for $\mathrm{PP} /$ pure silica composites. These results suggest that the higher the elastic modulus is, the better the fire behavior is. As reported in the literature $[24,25]$ such an improvement can be assigned to the accumulation of the inert additives near the surface then limiting the convection in the underlying polymer layer. Thus, this accumulation can act as a protective layer. Moreover, an increase of viscosity can prevent the gases transfer between the composite and the flame.

In order to confirm this hypothesis, other $\mathrm{PP} /$ silica composites (see section Preparation of PP composites) were tested with silica rates ranging from $10 \mathrm{wt} \%$ to $20 \mathrm{wt} \%$. First, it must be noted that pHRR were plotted versus the particles size, surface area, porosity and filler content for all these formulations. Those graphs (not presented here) show that fire behavior appears independent of the silica types but dependent of the filler content: the higher the filler content is, the lower the pHRR is. The reduced pHRR are plotted versus the reduced $\mathrm{G}^{\prime}$ in Fig. 17. Once again, it can be noted that the higher the elastic modulus is, the better the composites fire behavior is. The graph also reveals that $\mathrm{PP} /$ hydrophobic silica composite (PP-HDK-10\%) presents the worst behavior. Indeed despite the $10 \mathrm{wt} \%$ filler loading, the composite shows fire and rheological behaviors similar to the pure PP. The improvement of hydrophobic silica dispersion in the polymer matrix due to the increase of the silica/PP matrix interactions can explain the rheological behavior. The tendencies are equivalent for all silicas: the pHRR decreases quickly from the lowest filler loading to reach a minimum value with the highest silica rate. However the viscosity induced by non-porous silica Sidistar T120 in PP does not almost change whatever the filler content (the point corresponding to PP containing 15 wt\% of Sidistar T120 is out of the tendency, which may be due to uncertainties of measurement).

These results confirm the fact that to improve the fire behavior of PP, the viscosity of the polymer matrix must be high in order to limit bubbling and to allow forming a protective layer of silica at the sample surface. Moreover, the observation of the residues formed with those six different types of silica shows that the cohesion of the residual structure increases with the filler loading (Fig. 18). Therefore, in order to have a more effective physical effect of the inert additive, the silica content in the PP composites must be high enough to avoid creating cracks into the layer. This structure of residue was already described by Kashiwagi et al. [24]. When introducing $2 \mathrm{wt} \%$ of silica gel in PP, the residue is in form of powder. With $5 \mathrm{wt} \%$ and $10 \mathrm{wt} \%$, the authors observed that the formation of islets increases until silica compacted islands were formed by addition of $20 \mathrm{wt} \%$ of silica gel in PP.

\section{Conclusions}

The effect of pure and grafted silica incorporation in PP on the materials fire behavior was studied. It was shown by thermogravimetric analysis that all silicas are improving the thermal stability and particularly the thermo-oxidative stability of composite. Even though phosphorous grafted silica $\mathrm{Tm}$ and $\mathrm{Zm}$ provide a better thermo-oxidative stability in TGA, the incorporation of pure silica leads to better fire properties in cone calorimeter tests. Those

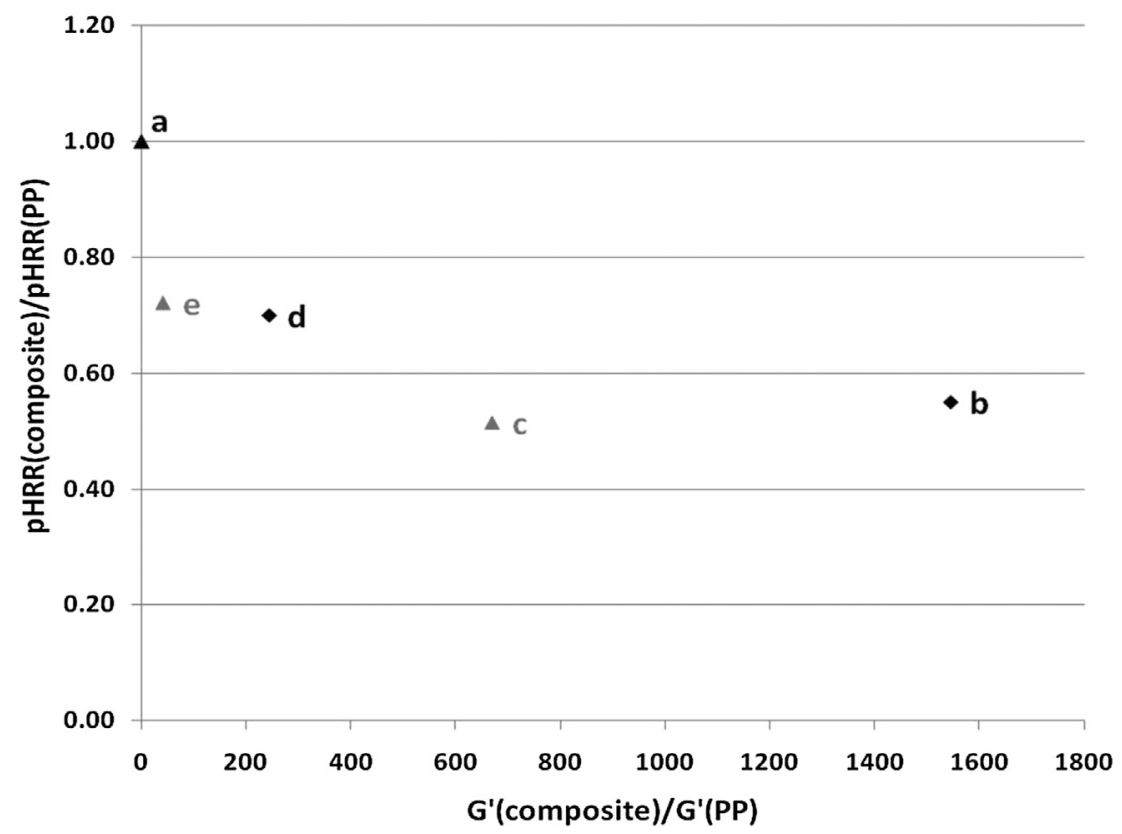

Fig. 16. Variation of reduced pHRR as a function of reduced $G^{\prime}$ for (a) PP, (b) PP-T-10\%, (c) P-Z-10\%, (d) PP-Tm-10\% and (e) PP-Zm-10\%. 


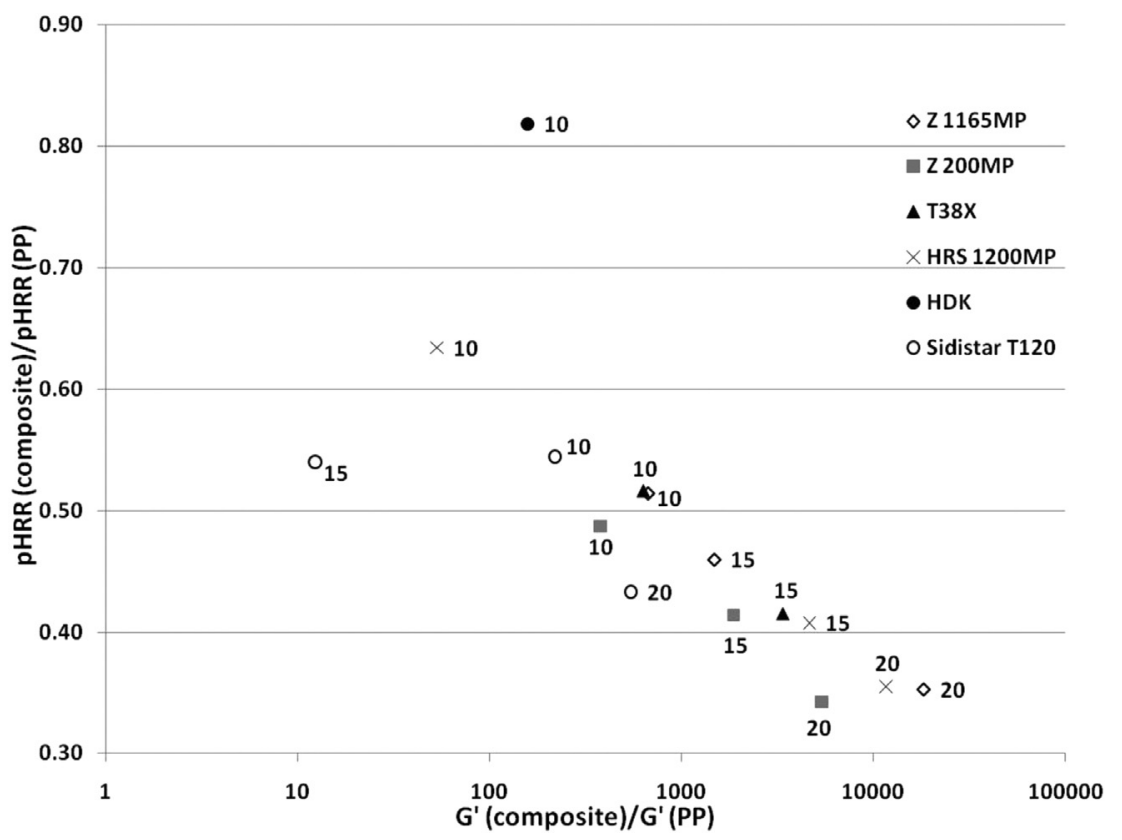

Fig. 17. Variation of reduced pHRR as a function of reduced $G^{\prime}$ for different $\mathrm{PP} /$ silica composites.

PP-Z-10\%

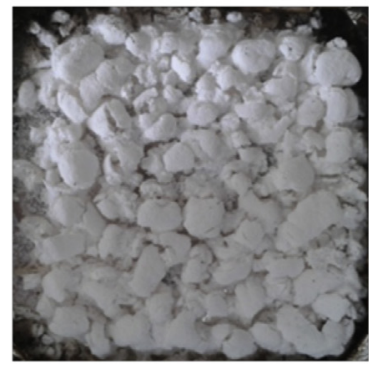

PP-Z-15\%

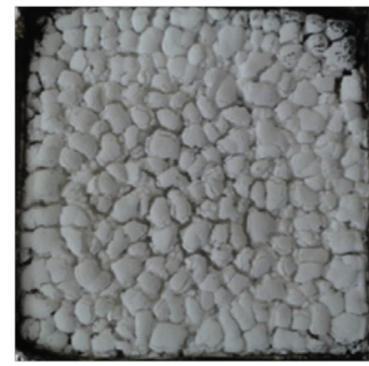

PP-Z-20\%

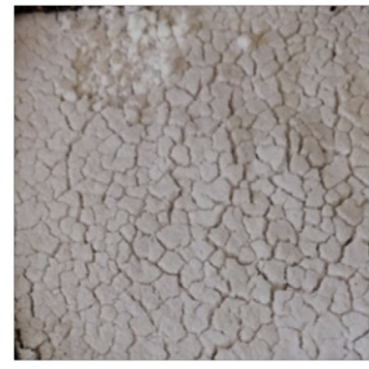

Fig. 18. Residue after cone calorimeter tests for PP-Z-10\%, PP-Z-15\% and PP-Z-20\%.

results reveal that the presence of phosphorus in small content does not have the expected chemical effects in gas and/or condensed phases. The PP/pure silica composites shows the most important reduction of peak of heat release rate that is to say a $20 \%$ decrease in PCFC and a 50\% decrease in cone calorimeter. The difference of TTI between PP/pure silica and PP/grafted silica composites $(10 \mathrm{~s})$ was explained by the appearance of bubbling after polymer melting for composites having the lowest TTI (PP-T-10\% and PP-Z-10\%).

It was shown that such an improvement of fire performances is mainly assigned to a barrier effect. This effect can be related to several interconnected factors including fillers dispersion and rheological behavior. Grafted silica seems to be more finely dispersed than pure silica due to the repulsion between particles. On the other hand, the pure silica is forming a network in the nonpolar polymer matrix because of the hydrogen bondings between silanols at the silica surface. Those different dispersions have an impact on rheological properties. A better dispersion leads to a lower composite viscosity. Finally, it seems that the composite viscosity has a strong effect on the fire performance in cone calorimeter: when the viscosity and the elasticity of the materials are high at low frequency (i.e. higher than $7.1 \times 10^{2} \mathrm{~Pa}$ ), the pHRR in cone calorimeter test is low (i.e. less than $662 \mathrm{~kW} / \mathrm{m}^{2}$ ). In fact, the higher the viscosity is, the lower the gas transfer between the composite and the flame is, thanks to the bubbling limitation and the faster accumulation of the inert additives near the surface.

This relationship between rheological and fire behaviors has been confirmed by using several types of silica introduced in PP with different loadings.

\section{Acknowledgments}

We thank the Region Rhône Alpes (France) and the University of Lyon (France) for financial support FUI SYRIMAP.

\section{References}

[1] D. Enescu, A. Frache, M. Lavaselli, O. Monticelli, F. Marino, Novel phosphorousnitrogen intumescent flame retardant system. Its effects on flame retardancy and thermal properties of polypropylene, Polym. Degrad. Stabil. 98 (2013) 297-305.

[2] B. Li, Z. Zhan, H. Zhang, C. Sun, Flame retardancy and thermal performance of polypropylene treated with the intumescent flame retardant, piperazine spirocyclic phosphoramidate, J. Vinyl Addit. Technol. 20 (2014) 10-15.

[3] H.J. Lin, H. Yan, B. Liu, L.Q. Wei, B.S. Xu, The influence of KH-550 on properties of ammonium polyphosphate and polypropylene flame retardant composites, Polym. Degrad. Stabil. 96 (2011) 1382-1388.

[4] P. Lv, Z. Wang, K. Hu, W. Fan, Flammability and thermal degradation of flame retarded polypropylene composites containing melamine phosphate and 
pentaerythritol derivatives, Polym. Degrad. Stabil. 90 (2005) 523-534.

[5] Y. Qian, P. Wei, P.K. Jiang, X.M. Zhao, H.Z. Yu, Synthesis of a novel hybrid synergistic flame retardant and its application in PP/IFR, Polym. Degrad. Stabil. 96 (2011) 1134-1140.

[6] X. Su, Y. Yi, J. Tao, H. Qi, Synergistic effect of zinc hydroxystannate with intumescent flame-retardants on fire retardancy and thermal behavior of polypropylene, Polym. Degrad. Stabil. 97 (2012) 2128-2135.

[7] K.-C. Tsai, C.-F. Kuan, C.-H. Chen, H.-C. Kuan, S.-W. Hsu, F.-M. Lee, et al., Study on thermal degradation and flame retardant property of halogen-free polypropylene composites using XPS and cone calorimeter, J. Appl. Polym. Sci. 127 (2012) 1084-1091.

[8] X.Y. Wang, Y. Li, W.W. Liao, J. Gu, D. Li, A new intumescent flame-retardant: preparation, surface modification, and its application in polypropylene, Polym. Adv. Technol. 19 (2008) 1055-1061.

[9] J. Yi, Y. Liu, D. Pan, X. Cai, Synthesis, thermal degradation, and flame retardancy of a novel charring agent aliphatic-aromatic polyamide for intumescent flame retardant polypropylene, J. Appl. Polym. Sci. 127 (2012) 1061-1068.

[10] J. Yi, H. Yin, X. Cai, Effects of common synergistic agents on intumescent flame retardant polypropylene with a novel charring agent, J. Therm. Anal. Calorim. 111 (2013) 725-734.

[11] S. Zhang, A.R. Horrocks, A review of flame retardant polypropylene fibres, Prog. Polym. Sci. 28 (2003) 1517-1538.

[12] R.N. Walters, S.M. Hackett, R.E. Lyon, Heats of combustion of high temperature polymers, Fire Mater. 24 (2000) 245-252.

[13] F. Laoutid, L. Bonnaud, M. Alexandre, J.M. Lopez-Cuesta, P. Dubois, New prospects in flame retardant polymer materials: from fundamentals to nanocomposites, Mater. Sci. Eng. R: Reports 63 (2009) 100-125.

[14] D. Bikiaris, A. Vassiliou, K. Chrissafis, K.M. Paraskevopoulos, A. Jannakoudakis, A. Docoslis, Effect of acid treated multi-walled carbon nanotubes on the mechanical, permeability, thermal properties and thermo-oxidative stability of isotactic polypropylene, Polym. Degrad. Stabil. 93 (2008) 952-967.

[15] Z. Fang, P. Song, L. Tong, Z. Guo, Thermal degradation and flame retardancy of polypropylene/C60 nanocomposites, Thermochim. Acta 473 (2008) 106-108.

[16] A. Fina, D. Tabuani, G. Camino, Polypropylene-polysilsesquioxane blends, Eur. Polym. J. 46 (2010) 14-23.

[17] J. Golebiewski, A. Galeski, Thermal stability of nanoclay polypropylene composites by simultaneous DSC and TGA, Compos. Sci. Technol. 67 (2007) 3442-3447.

[18] H. Palza, R. Vergara, P. Zapata, Improving the thermal behavior of poly(propylene) by addition of spherical silica nanoparticles, Macromol. Mater Eng. 295 (2010) 899-905.

[19] F.G. Ramos Filho, T.J.A. Mélo, M.S. Rabello, S.M.L. Silva, Thermal stability of nanocomposites based on polypropylene and bentonite, Polym. Degrad. Stabil. 89 (2005) 383-392.

[20] X. Wen, Y. Wang, J. Gong, J. Liu, N. Tian, Y. Wang, et al., Thermal and flammability properties of polypropylene/carbon black nanocomposites, Polym. Degrad. Stabil. 97 (2012) 793-801.

[21] F. Zhu, D. Liu, G. Cai, X. Tan, J. Wang, H. Lu, et al., Thermal stability and flammability performance of polypropylene composites with silica pillared montmorillonites, Polym. Adv. Technol. 25 (2014) 211-216.

[22] T. Kashiwagi, E. Grulke, J. Hilding, K. Groth, R. Harris, K. Butler, et al., Thermal and flammability properties of polypropylene/carbon nanotube nanocomposites, Polymer 45 (2004) 4227-4239.

[23] J.W. Gilman, T. Kashiwagi, M.R. Nyden, R.H. Harris Jr., New Flame Retardants Consortium: Flame Retardant Mechanism of Silica, Final Report (NISTIR 6357), 1999.

[24] T. Kashiwagi, J.W. Gilman, K.M. Butler, R.H. Harris, J.R. Shields, A. Asano, Flame retardant mechanism of silica gel/silica, Fire Mater. 24 (2000) 277-289.

[25] T. Kashiwagi, J.R. Shields, R.H. Harris, R.D. Davis, Flame-retardant mechanism of silica: effects of resin molecular weight, J. Appl. Polym. Sci. 87 (2003) 1541-1553.

[26] T. Kashiwagi, M. Mu, K. Winey, B. Cipriano, S.R. Raghavan, S. Pack, et al., Relation between the viscoelastic and flammability properties of polymer nanocomposites, Polymer 49 (2008) 4358-4368.

[27] L. Clerc, L. Ferry, E. Leroy, J-M. Lopez-Cuesta, Influence of talc physical properties on the fire retarding behaviour of (ethylene-vinyl acetate copolymer/magnesium hydroxide/talc) composites, Polym. Degrad. Stabil. 88 (2005) 504-511.

[28] F. Laoutid, L. Ferry, E. Leroy, J.M. Lopez Cuesta, Intumescent mineral fire retardant systems in ethylene-vinyl acetate copolymer: effect of silica particles on char cohesion, Polym. Degrad. Stabil. 91 (2006) 2140-2145.

[29] F. Carpentier, S. Bourbigot, M. Le Bras, R. Delobel, Rheological investigations in fire retardancy: application to ethylene-vinyl-acetate copolymer-magnesium hydroxide/zinc borate formulations, Polym. Int. 49 (2000) 1216-1221.

[30] T. Kashiwagi, F. Du, J.F. Douglas, K.I. Winey, R.H. Harris, J.R. Shields, Nanoparticle networks reduce the flammability of polymer nanocomposites, Nat. Mater. 4 (2005) 928-933.

[31] M. Batistella, B. Otazaghine, R. Sonnier, A.-S. Caro-Bretelle, C. Petter, J.M. Lopez-Cuesta, Fire retardancy of ethylene vinyl acetate/ultrafine kaolinite composites, Polym. Degrad. Stabil. 100 (2014) 54-62.

[32] A. Fina, J. Feng, F. Cuttica, In-depth radiative heat transmittance through polypropylene/nanoclay composites, Polym. Degrad. Stabil. 98 (2013)
1030-1035.

33] T. Mariappan, C.A. Wilkie, Combinations of elements: a new paradigm for fire retardancy, Macromol. Chem. Phys. 213 (2012) 1987-1995.

[34] Q. Dong, Y. Ding, B. Wen, F. Wang, H. Dong, S. Zhang, et al., Improvement of thermal stability of polypropylene using DOPO-immobilized silica nanoparticles, Colloid Polym. Sci. 290 (2012) 1371-1380.

[35] Q. Dong, M. Liu, Y. Ding, F. Wang, C. Gao, P. Liu, et al., Synergistic effect of DOPO immobilized silica nanoparticles in the intumescent flame retarded polypropylene composites, Polym. Adv. Technol. 24 (2013) 732-739.

[36] J.L. Valentin, M.A. Lopez-Manchado, P. Posadas, A. Rodriguez, A. Marcos-Fernandez, L. Ibarra, Characterization of the reactivity of a silica derived from acid activation of sepiolite with silane by 29Si and 13C solid-state NMR, J. Colloid Interf. Sci. 298 (2006) 794-804.

[37] C. Huggett, Estimation of rate of heat release by means of oxygen consumption measurements, Fire Mater. 4 (1980) 61-65.

[38] Lyon R., Janssens M., Polymer Flammability, DOT/FAA/AR-05/14

[39] F. Carniato, G. Paul, C. Bisio, S. Caldarelli, L. Marchese, On the organic/inorganic interface between mesoporous SBA-16 silica and its structural directing polymer: a combined FT-IR and solid state NMR study, RSC Adv. 2 (2012) 1153-1160.

[40] V. Bounor-Legaré, C. Angelloz, P. Blanc, P. Cassagnau, A. Michel, A new route for organic-inorganic hybrid material synthesis through reactive processing without solvent, Polymer 45 (2004) 1485-1493.

[41] E. Lippmaa, M. Maegi, A. Samoson, G. Engelhardt, A.R. Grimmer, Structural studies of silicates by solid-state high-resolution silicon-29 NMR, J. Am. Chem. Soc. 102 (1980) 4889-4893.

[42] G.E. Maciel, D.W. Sindorf, Silicon-29 NMR study of the surface of silica gel by cross polarization and magic-angle spinning, J. Am. Chem. Soc. 102 (1980) 7606-7607.

43] P. Theil-Van Nieuwenhuyse, V. Bounor-Legaré, P. Bardollet, P. Cassagnau, A. Michel, L. David, et al., Phosphorylated silica/polyamide 6 nanocomposites synthesis by in situ sol-gel method in molten conditions: impact on the fireretardancy, Polym. Degrad. Stabil. 98 (2013) 2635-2644.

[44] S. Berger, S. Braun, H.-O. Kalinowski, NMR Spectroscopy of the Non-metallic Elements, John Wiley and Sons, 1997.

[45] J. Alongi, C. Colleoni, G. Rosace, G. Malucelli, Thermal and fire stability of cotton fabrics coated with hybrid phosphorus-doped silica films, J. Therm. Anal. Calorim. 110 (2012) 1207-1216.

[46] C. Bartholome, E. Beyou, E. Bourgeat-Lami, P. Cassagnau, P. Chaumont L. David, et al., Viscoelastic properties and morphological characterization of silica/polystyrene nanocomposites synthesized by nitroxide-mediated polymerization, Polymer 46 (2005) 9965-9973.

[47] P. Cassagnau, Melt rheology of organoclay and fumed silica nanocomposites Polymer 49 (2008) 2183-2196.

[48] M. Zanetti, G. Camino, P. Reichert, R. Mülhaupt, Thermal behaviour of poly(propylene) layered silicate nanocomposites, Macromol. Rapid Commun. 22 (2001) 176-180.

[49] S. Jacob, K.K. Suma, J.M. Mendez, K.E. George, Reinforcing effect of nanosilica on polypropylene-nylon fibre composite, Mater. Sci. Eng. B 168 (2010) $245-249$.

[50] B. Azinfar, S.A. Ahmad Ramazani, N. Jafariesfad, In situ preparation an property investigation of polypropylene/fumed silica nanocomposites, Polym. Compos. 35 (2014) 37-44.

[51] J. Li, R. Yang, J. Yu, Y. Liu, Deterioration of polypropylene/silicon dioxide nanocomposites before oxidative degradation, J. Appl. Polym. Sci. 113 (2009) 601-606.

[52] R. Sonnier, B. Otazaghine, L. Ferry, J.-M. Lopez-Cuesta, Study of the combustion efficiency of polymers using a pyrolysis-combustion flow calorimeter, Combust. Flame 160 (2013) 2182-2193.

[53] B. Schartel, K.H. Pawlowski, R.E. Lyon, Pyrolysis combustion flow calorimeter: a tool to assess flame retarded PC/ABS materials? Thermochim. Acta 462 (2007) 1-14.

[54] R. Sonnier, L. Ferry, C. Longuet, F. Laoutid, B. Friederich, A. Laachachi, et al, Combining cone calorimeter and PCFC to determine the mode of action of flame-retardant additives, Polym. Adv. Technol. 22 (2011) 1091-1099.

[55] T.D. Hapuarachchi, T. Peijs, E. Bilotti, Thermal degradation and flammability behavior of polypropylene/clay/carbon nanotube composite systems, Polym. Adv. Technol. 24 (2012) 331-338.

[56] A. Fina, G. Camino, Ignition mechanisms in polymers and polymer nanocomposites, Polym. Adv. Technol. 22 (2011) 1147-1155.

[57] E.S. Oztekin, S.B. Crowley, R.E. Lyon, S.I. Stoliarov, P. Patel, T.R. Hull, Sources of variability in fire test data: A case study on poly(aryl ether ether ketone) (PEEK), Combust. Flame 159 (2012) 1720-1731.

[58] M. Fu, B. Qu, Synergistic flame retardant mechanism of fumed silica in ethylene-vinyl acetate/magnesium hydroxide blends, Polym. Degrad. Stabil. 85 (2004) 633-639.

[59] X.J. Lai, X.R. Zeng, H.Q. Li, C.Y. Yin, H.L. Zhang, F. Liao, Synergistic effect of phosphorus-containing nanosponges on intumescent flame-retardant poly propylene, J. Appl. Polym. Sci. 125 (2011) 1758-1765.

[60] J.W. Gilman, Flammability and thermal stability studies of polymer layeredsilicate (clay) nanocomposites, Appl. Clay Sci. 15 (1999) 31-49. 